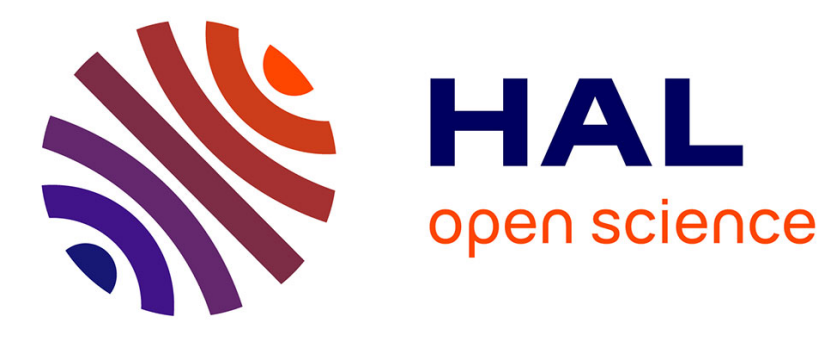

\title{
The Legacy of Recurrent Introgression during the Radiation of Hares
}

\author{
Mafalda Ferreira, Matthew Jones, Colin Callahan, Liliana Farelo, Zelalem \\ Tolesa, Franz Suchentrunk, Pierre Boursot, L Scott Mills, Paulo Alves, Jeffrey \\ Good, et al.
}

\section{To cite this version:}

Mafalda Ferreira, Matthew Jones, Colin Callahan, Liliana Farelo, Zelalem Tolesa, et al.. The Legacy of Recurrent Introgression during the Radiation of Hares. Systematic Biology, 2020, 70, pp.593-607. 10.1093/sysbio/syaa088 . hal-03036881

\section{HAL Id: hal-03036881 https://hal.science/hal-03036881}

Submitted on 2 Dec 2020

HAL is a multi-disciplinary open access archive for the deposit and dissemination of scientific research documents, whether they are published or not. The documents may come from teaching and research institutions in France or abroad, or from public or private research centers.
L'archive ouverte pluridisciplinaire HAL, est destinée au dépôt et à la diffusion de documents scientifiques de niveau recherche, publiés ou non, émanant des établissements d'enseignement et de recherche français ou étrangers, des laboratoires publics ou privés. 


\section{Running head: Introgression in Hares}

\section{Title: The Legacy of Recurrent Introgression during the Radiation of Hares}

Mafalda S. Ferreira ${ }^{1,2,3}$, Matthew R. Jones ${ }^{3}$, Colin M. Callahan ${ }^{3}$, Liliana Farelo ${ }^{1}$, Zelalem

Tolesa $^{4}$, Franz Suchentrunk ${ }^{5}$, Pierre Boursot ${ }^{6}$, L. Scott Mills ${ }^{7,8,9}$, Paulo C. Alves ${ }^{1,2,7}$, Jeffrey

M. Good ${ }^{3,7, *}$, José Melo-Ferreira ${ }^{1,2, *}$

${ }^{1}$ CIBIO, Centro de Investigação em Biodiversidade e Recursos Genéticos, InBIO Laboratório Associado, Universidade do Porto, Vairão, Portugal.

${ }_{2}^{2}$ Departamento de Biologia, Faculdade de Ciências da Universidade do Porto, Porto,

Portugal.

${ }^{3}$ Division of Biological Sciences, University of Montana, Missoula, Montana, USA.

${ }^{4}$ Department of Biology, Hawassa University, Hawassa, Ethiopia.

${ }^{5}$ Research Institute of Wildlife Ecology, University of Veterinary Medicine Vienna, Vienna,

Austria.

${ }^{6}$ Institut des Sciences de l'Évolution Montpellier (ISEM), Université Montpellier, CNRS, IRD, EPHE, France.

${ }^{7}$ Wildlife Biology Program, College of Forestry and Conservation, University of Montana, Missoula, Montana, USA.

${ }^{8}$ Office of Research and Creative Scholarship, University of Montana, Missoula, Montana, USA.

${ }^{9}$ Fisheries, Wildlife, and Conservation Biology Program, Department of Forestry and Environmental Resources, North Carolina State University, Raleigh, North Carolina, USA. *Shared senior authorship. 


\title{
Ferreira et al.
}

Correspondence: Mafalda S. Ferreira, mafaldasferreira@ cibio.up.pt; Jeffrey M. Good, jeffrey.good@umontana.edu; José Melo-Ferreira, jmeloferreira@cibio.up.pt

\begin{abstract}
Hybridization may often be an important source of adaptive variation, but the extent and long-term impacts of introgression have seldom been evaluated in the phylogenetic context of a radiation. Hares (Lepus) represent a widespread mammalian radiation of 32 extant species characterized by striking ecological adaptations and recurrent admixture. To understand the relevance of introgressive hybridization during the diversification of Lepus, we analyzed whole exome sequences $(61.7 \mathrm{Mb})$ from 15 species of hares (1- 4 individuals per species), spanning the global distribution of the genus, and two outgroups. We used a coalescent framework to infer species relationships and divergence times, despite extensive genealogical discordance. We found high levels of allele sharing among species and show that this reflects extensive incomplete lineage sorting and temporally layered hybridization. Our results revealed recurrent introgression at all stages along the Lepus radiation, including recent gene flow between extant species since the last glacial maximum, but also pervasive ancient introgression occurring since near the origin of the hare lineages. We show that ancient hybridization between northern hemisphere species has resulted in shared variation of potential adaptive relevance to highly seasonal environments, including genes involved in circadian rhythm regulation, pigmentation, and thermoregulation. Our results illustrate how the genetic legacy of ancestral hybridization may persist across a radiation, leaving a longlasting signature of shared genetic variation that may contribute to adaptation.
\end{abstract}

\section{KEYWORDS}




\section{Introgression in Hares}

Ancient introgression; Hybridization; Adaptation; Phylogenomics; Lepus

Species radiations are often accompanied by extensive gene flow between nascent lineages (e.g., Lamichhaney et al. 2015; Árnason et al. 2018; Malinsky et al. 2018; Li et al. 2019; Barth et al. 2020). Genetic signatures of hybridization between several closely related species could either represent recent or ongoing introgressive hybridization (Eaton et al. 2015), or the remnants of hybridization among ancestral populations that remain shared among contemporary species (Malinsky et al. 2018; Li et al. 2019). Although these alternatives can be difficult to differentiate in large radiations (Eaton et al. 2015; Malinsky et al. 2018; Vanderpool et al. 2020), both ancient and contemporary introgression has been linked to local adaptation in several systems (e.g., Liu et al. 2015; Gittelman et al. 2016; Meier et al. 2017; Barlow et al. 2018; Giska et al. 2019; Svardal et al. 2020). Thus, unraveling the tempo and contribution of introgression to standing genetic variation within and among species remains a critical step in understanding the overall importance of introgression to evolution.

Reconstructing the history of hybridization between several closely related species requires inferring evolutionary relationships among species while considering the two primary processes - incomplete lineage sorting and gene flow - that may cause sharing of genetic variation among populations (Malinsky et al. 2018). The network multispecies coalescent (NMSC) model (Than et al. 2011; Solís-Lemus et al. 2017; Degnan 2018) offers one promising framework that appears to resolve species relationships in the face of multiple reticulation events and rapid speciation (Kozak et al. 2018; Edelman et al. 2019). However, the NMSC is still prohibitive for large datasets and relies on the user to choose the number of migration events based on a priori hypotheses (Yu and Nakhleh 2015). Alternatively, sitebased summary statistics based on tree asymmetries (e.g., Green et al. 2010; Pease and Hahn 


\section{Ferreira et al.}

2015), or admixture proportions (e.g., Reich et al. 2009; Martin et al. 2015; Malinsky et al. 2018) are simpler to implement, but offer less power for localizing the timing and number of introgression events when recurrent hybridization is layered across a phylogeny (Malinsky et al. 2018). A combination of methods is thus most appropriate to infer a species tree that may have layered events of hybridization throughout time (e.g., Kozak et al. 2018; Malinsky et al. 2018; Edelman et al. 2019; Li et al. 2019).

Hares and jackrabbits comprise a group of 32 currently classified species (genus Lepus; Smith et al. 2018) whose common ancestor likely originated in North America and spread throughout most of the Northern Hemisphere and Africa presumably in the last 4-6 million years (Yamada et al. 2002; Matthee et al. 2004; Melo-Ferreira et al. 2012). Hares are primarily associated with open grasslands, but can be found across a broad range of biomes (e.g., desert, forest, or arctic) and elevations (e.g., from sea level to the Himalayan or Ethiopian plateau; Smith et al., 2018). The Lepus radiation also provides multiple case studies of hybridization and introgression, with admixture detected among several extant pairs of species (e.g., Liu et al. 2011; Melo-Ferreira et al. 2012; Tolesa et al. 2017; Jones et al. 2018; Seixas et al. 2018; Lado et al. 2019; Kinoshita et al. 2019). Selection on introgressed variation has been hypothesized to have aided the range expansion of the Iberian hare (Seixas et al. 2018), and has been directly linked to convergent adaptive evolution of non-white winter coats in populations of two species that change the color of their pelage seasonally (Jones et al. 2018, 2020a; Giska et al. 2019). These studies suggest that the relatively recent exchange of genetic variation among extant Lepus species has provided an important source of adaptive variation. However, the phylogenetic relationships among Lepus species remain poorly resolved (Halanych et al. 1999; Matthee et al. 2004; Melo-Ferreira et al. 2012; Melo-Ferreira and Alves 2018), and the contribution of ancient gene flow to the Lepus evolutionary history remains unknown. 


\section{Introgression in Hares}

Here, we use exome-wide data to infer the evolutionary history of 15 Lepus species and show that hybridization between lineages has likely occurred since the origin of the radiation. The combination of incomplete lineage sorting and these temporally layered events of hybridization have resulted in extremely high levels of shared genetic variation among extant species, including species that currently occur on different continents. We then use the case of ancient admixture among northern latitude species that occupy highly seasonal environments to investigate the gene content and possible functional relevance of introgressed genomic regions. Our work demonstrates that recurrent introgression throughout evolutionary history has made a substantial contribution to genetic variation within and among species of this widespread mammalian radiation.

\section{MATERIALS AND MethodS}

\section{Taxon Sampling and Exome Sequencing}

We generated new genome-wide resequencing data targeting 207,691 exonic and noncoding regions [totaling 61.7 Megabases (Mb) total] from 14 hare species (30 individuals) and the outgroup pygmy rabbit (Brachylagus idahoensis; 2 individuals). We combined these data with published whole exomes from four snowshoe hares [Lepus americanus; NCBI Sequence Read Archive BioProject PRJNA420081 from Jones et al. (2018, 2020b)] and extracted data from the reference genome of the European rabbit (Oryctolagus cuniculus; OryCun2.0; Carneiro et al., 2014) to use as a second outgroup. Our total sample of 15 hare species (34 individuals, 1 to 4 individuals per species) and 2 outgroup species (3 individuals) included species from all major regions of the Lepus native distribution: Africa (3 species), Africa and Eurasia (1 species), Eurasia (6 species) and North America (5 species, see Fig. 1 and Supplementary Table S1 available on Dryad; doi:10.5061/dryad.bzkh18967). 


\section{Ferreira et al.}

Exome capture experiments were performed following the procedures outlined in Jones et al. (2018) and in the Supplementary Material and Methods. Briefly, we obtained samples as tissue or extracted DNA including samples from previous studies or through loans from collaborators (Supplementary Table S1). Depending on the sample, genomic DNA was isolated using a saline extraction method (Sambrook et al. 1989) or DNeasy Blood \& Tissue Kit (Qiagen) (Supplementary Table S1 and Supplementary Materials and Methods). We prepared Illumina sequencing libraries for each sample following Meyer and Kircher (2010) with minor modifications [see Supplementary Material and Methods and Jones et al. (2018)]. Sequencing libraries were then enriched using NimbleGen SeqCap EZ v.4.3 protocol and a custom capture design consisting of 213,164 probes targeting $\sim 25 \mathrm{Mb}$ of protein-coding exons, $\sim 28 \mathrm{Mb}$ of untranslated regions, and $\sim 9 \mathrm{Mb}$ of intron/intergenic regions (Jones et al. 2018). Hybridization reactions were performed in two separate equimolar pools of indexed libraries (31 and 29 libraries, Supplementary Table S1), together with samples used for other studies. The target enriched pools were each sequenced across two lanes of an Illumina HiSeq1500 sequencer (125 bp paired-end reads) at CIBIO-InBIO’s New-Gen sequencing platform, Portugal.

\section{Read Processing and Genotyping}

We trimmed adapters, low-quality bases, merged overlapping reads, and removed PCR duplicates from raw reads using the expHTS pipeline (v.0.Mar112016; https://github.com/msettles/expHTS). We then used pseudo-it (v1; Sarver et al. 2017) to generate pseudo-reference exomes for each species by iteratively mapping (four iterations and allowing ambiguity codes) cleaned single and paired-end reads from one individual per species (Supplementary Table S1) to the European rabbit reference genome (OryCun2.0) (Carneiro et al. 2014). For snowshoe hares and black-tailed jackrabbits (L. californicus), we 


\section{Introgression in Hares}

used pseudo-references generated by Jones et al. (2018). The genomes of hares and European rabbits are broadly syntenic despite two known large scale fusions/fissions (Robinson et al. 2002) and sufficiently closely related that iterative mapping to the rabbit reference is not expected to bias genotyping (Sarver et al. 2017; Marques et al. 2020).

We then mapped data from all individuals to each species-specific pseudo-reference using bwa-mem (v.0.7.12-r1039; Li 2013) with default options. Mapped reads were sorted with samtools (v1.4; Li et al. 2009), assigned to read groups, filtered for duplicates (Picard v1.140; http://broadinstitute.github.io/picard/), and realigned for insertion-deletion length variation using GATK (v3.4.46; Van der Auwera et al. 2013). We calculated coverage statistics and capture efficiency using CalculateHSMetrics from Picard. For each individual, we called and filtered genotypes using the bcftools (v1.4; Li 2011) mpileup, call and filter pipeline. We excluded indels and filtered single nucleotide variant genotypes with low mapping (MQ < 20) or phred-scaled quality (QUAL < 20), low sequencing depth (DP < 6), excess sequencing depth (3x individual coverage, see Supplementary Table S2), sites less than 10 bases from an indel (--SnpGap 10), and low quality non-reference homozygous or heterozygous genotypes (GQ $<=20)$. We used the filtered genotypes to construct consensus exome fasta sequences in the OryCun2.0 coordinate system.

\section{Species Tree Inference}

We used a concatenated alignment without missing data to estimate a single bifurcating phylogeny using a maximum likelihood (ML) search and rapid bootstrapping run under the GTR $+\Gamma$ model of sequence evolution (autoMRE option) in $R A x M L$ (v8.2.10; Stamatakis 2018). We then used two complementary methods to infer multispecies-coalescent trees while accounting for local variation in phylogenetic histories along the genome. First, we extracted 50 kilobase $(\mathrm{kb})$ alignments from the exome capture targeted regions plus 200 


\section{Ferreira et al.}

base pairs (bp) of flanking sequences using $m s a \_s p l i t$ (phast (1.4;

http://compgen.cshl.edu/phast/) and bedtools (1.9; Quinlan and Hall 2010), considering a balance between the expected extent of linkage disequilibrium in hares (10-20 kb; Jones et al. 2018) and the retention of information for phylogenetic analysis (alignment length $>1 \mathrm{~kb}$ ). For each window, we filtered positions with missing data for $>30 \%$ of individuals using TriSeq (TriFusion 1.0.0; http://odiogosilva.github.io/TriFusion/), excluded windows smaller than $1 \mathrm{~kb}$, and used $R A x M L$ to estimate local maximum likelihood gene trees $(\mathrm{GTR}+\Gamma, 100$ bootstraps). For each gene tree, we used the corresponding bootstraps to calculate a tree certainty score based on the sum of certainty scores for all internodes of a tree (-L MRE option in RAxML; Salichos and Rokas 2013; Salichos et al. 2014; Kobert et al. 2016). The internode certainty score weighs the support of the bipartition represented by a given internode in the gene tree against the support of the second most prevalent conflicting bipartition (Salichos et al. 2014) present in the bootstrap trees. In our case, the maximum theoretical value of the tree certainty score is 31 , or $\mathrm{k}-3$ with $\mathrm{k}$ equal to the number of taxa (Salichos et al. 2014). Only trees with certainty score above 5 were used in the species tree inference. We unrooted the gene trees using R package ape (Paradis et al. 2004) and estimated a consensus species tree using ASTRAL-III (5.6.3; Zhang et al. 2018).

We also estimated coalescent species trees using only variable sites with SVDquartets (Chifman and Kubatko 2014) implemented in PAUP*(4a163; Swofford 2003). For the analyses based on variable sites, we recovered single nucleotide variants (SNVs) distanced 10 $\mathrm{kb}$ along the genome (within targeted regions and $200 \mathrm{bp}$ flanking regions) using snp-sites (v2.3.3; Page et al. 2016), a custom script and bedtools intersect, and excluded sites with missing information for $>30 \%$ of the individuals using a custom script (available at https://github.com/evochange). For both SVDquartets and ASTRAL analyses, species trees were estimated with and without assigning species identities and using sites/intervals genome- 


\section{Introgression in Hares}

wide or only from the $\mathrm{X}$ chromosome. The European and/or pygmy rabbits were included for all analyses requiring outgroups. Additional details on the phylogenetic analyses are provided in the Supplementary Materials and Methods.

\section{Bayesian Divergence Time Inference}

We performed Bayesian inference of divergence times in the inferred species tree using an approximate maximum likelihood method and assuming an autocorrelated relaxed molecular clock, implemented in MCMCtree (PAML v.4.9; Yang 2007) and described in dos Reis and Yang $(2011,2019)$. For one individual per species (Supplementary Table S1), we extracted the coding sequence for all genes included in our capture design $(18,798$ genes in the OryCun2.0 ENSEMBLE 94 database) with bedtools getfasta, after selecting the longest transcript per gene using R package biomaRt (v2.34.2; Durinck et al. 2005, 2009). We excluded alignments with more than $20 \%$ missing data using AMAS (Borowiec 2016) (see Supplementary Materials and Methods available on Dryad for details). With these, we constructed a concatenated alignment with three partitions, corresponding to the three codon positions. We assumed GTR $+\Gamma$ for the model of sequence evolution and we used the prior of 3.33 for the average substitution rate per site per 100 million years, following Matthee et al. (2004). Lepus is poorly represented in the fossil record. The earliest hare record dates to the early Pleistocene [2.5 million years ago (Ma); White 1991; Lopez-Martinez 2008], which is much more recent than molecular estimates for the genus extrapolated from deeper fossil calibrations (4-6 Ma; Yamada et al. 2002). Therefore, we used two different calibrations for the species tree. We either (1) used molecular estimates of 4-6 million years (myr) for the most recent common ancestor (TMRCA) of Lepus extrapolated from deep fossil record calibrations of the order Lagomorpha (Yamada et al. 2002) and 9.7-14.5 myr for the TMRCA of Oryctolagus-Lepus divergence (Matthee et al. 2004) or (2) used fossil estimates of 2.5 myr 


\section{Ferreira et al.}

for the lower bound of Lepus diversification and constrained the root to be no older than 4.8 myr, which is when the fossil record suggests that the common ancestor of rabbits and hares existed (Hibbard 1963; White 1991). We discarded the first 1,000,000 samples as burn-in and ran the program until we gathered 1,000,000 samples from the posterior, sampling every 10 iterations, and repeated the analysis twice to ensure convergence. We checked for lack of convergence between the two runs by confirming a linear correlation between posterior times, trendless trace plots, and high effective sample size values $(\mathrm{ESS}>200)$ following dos Reis and Yang (2019). Finally, we also checked for a linear relationship between posterior times and confidence interval widths in infinite sites plots (Inoue et al. 2010).

\section{Ancestral Range Reconstruction}

We used the R package BioGeoBEARS (Matzke 2013, 2014a, 2014b) to estimate ancestral ranges for the species in our dated phylogenies. For this analysis, we assigned each species to North America, Eurasia or Africa. Note that the Cape hare sensu lato is distributed in Africa and Eurasia, but Lado et al. (2019) showed deep divergence and non-monophyly of African and Eurasian lineages. Because our Cape hare samples represent the African lineages, we assigned the Cape hare distribution to Africa. In BioGeoBEARS, we implemented a maximum likelihood framework to estimate ancestral ranges under three biogeographical models: DEC (dispersal-extinction-cladogenesis; Ree and Smith 2008), DIVA (dispersalvicariance analysis; Ronquist 1997) and BayArea (Bayesian Inference of Historical Biogeography for Discrete Areas; Landis et al. 2013). For each method, we tested each model with and without founder-event speciation ( $j$ parameter; Matzke 2014b), resulting in six models in total: DEC, DEC+J, DIVALIKE, DIVALIKE+J, BAYAREALIKE and BAYAREALIKE+J. The best fitting model was assessed with the likelihood ratio test (LRT), the Akaike Information criterion (AIC) and corrected AIC (AICc). 


\section{Introgression in Hares}

\section{Gene Tree Discordance and Phylogenetic Networks}

We performed a series of analyses to explore the amount and effect of gene tree discordance in our dataset. To minimize misinterpreting poor phylogenetic resolution as discordance, we retained only the filtered gene trees used as input for ASTRAL. These trees were used to estimate a SplitsTree4 network (v4.14.6; Huson and Bryant 2006) with the option "Consensus Network with distances as means" and a 5\% weight threshold to draw a split, and a majority rule consensus tree with $R A x M L$ (-L MRE option), including internode certainty scores (Salichos et al. 2014). We then used DiscoVista (Sayyari et al. 2018) to plot ASTRAL quartet frequencies around nodes of interest. Finally, we calculated Robinson-Foulds normalized distances between gene trees and the ASTRAL species tree where individuals are not assigned to species, and among gene trees using the function $R F$.dist() from the $\mathrm{R}$ package phangorn (2.4.0; Schliep 2011). This metric varies between 0 (no discordance between trees) and 1 (complete discordance).

We used PhyloNet (v3.6.6; Yu and Nakhleh 2015) to model species relationships under the network multispecies coalescent model, using all local genealogies (tree certainty scores > 5). Given our extensive dataset, we applied the pseudo-maximum likelihood inference of species networks ( $\mathrm{Yu}$ and Nakhleh 2015). We ran InferNetwork_MPL (Yu and Nakhleh 2015) with 0 up to 4 migration events (due to computational limitations), associating individuals to species (option -a), and optimizing branch lengths and inheritance probabilities to compute likelihoods for each proposed network (option -o). We used the best likelihoods per run to calculate BIC and AICc following Yu et al. $(2012,2014)$ to compare the resulting networks. Networks were visualized with IcyTree (https://icytree.org; last accessed July 2019). 


\section{Ferreira et al.}

Given that the pseudo-maximum likelihood network inference is computationally intensive (Yu and Nakhleh 2015), network support could not be inferred with bootstraps. Therefore, we additionally used Treemix and 'f-branch' statistics (see below) to determine if ancestral reticulations were consistently inferred across methods. We reconstructed ancestral population graphs with TreeMix (v1.13, options -global, -noss and -se; Pickrell and Pritchard 2012) following the steps used to generate an SNV dataset for SVDQuartets but only including Lepus species. We randomly phased the SNV alignments with a custom script (available at https://github.com/evochange) and created the TreeMix input using the script TreeMix_from_nex.py (https://github.com/mgharvey). We allowed 0 to 9 migration events and used the white-sided jackrabbit (L. callotis) as the outgroup relative to all other Lepus species (see Results).

\section{Genetic Diversity, Divergence, and Admixture}

We used the genomics general toolkit (https://github.com/simonhmartin/; last accessed January 14,2019$)$ to estimate pairwise genetic distances $\left(\mathrm{d}_{\mathrm{xy}}\right)$ between species and nucleotide diversity $(\pi)$ within species, and a custom script (available at https://github.com/evochange) to calculate the number of heterozygous sites per individual and the subset shared between at least one individual of each pair of species (used as proxy for shared variation). All diversity estimates were based on a genome-wide concatenated alignment, where we excluded sites with missing information for $>30 \%$ of the individuals.

We then used genomics general and custom scripts (available at https://github.com/evochange) to calculate several variants of the D-statistics (Green et al. 2010) from the informative sites in the same filtered alignment, treating the European rabbit sequence as the ancestral state (additional details are provided in the Supplementary Materials and Methods). Briefly, we calculated the minimum absolute value of $\mathrm{D}\left(\mathrm{D}_{\min }\right)$ (Malinsky et al. 


\section{Introgression in Hares}

2018) for all possible species trios. We calculated z-scores for each $D$ value using a $1 \mathrm{Mb}$ block jackknife approach. After finding the minimum D per trio, D values with Bonferronicorrected $P \leq 0.05$ were considered significantly different from zero. We then calculated the 'f-branch' statistic $\left(f_{b}(C)\right)$ (Malinsky et al. 2018). The 'f-branch' statistic measures admixture proportion between species $C$ and branch $b$ by calculating admixture proportion among all possible $f(\mathrm{~A}, \mathrm{~B}, \mathrm{C}, \mathrm{O})$ combinations where $A$ are all descendants of branch $a$ (sister to $b$ ), $B$ are all descendants of branch $b$, and $C$ is the donor taxa. $f_{b}(C)$ is the minimum $f$ value across all possible $B$ and the median across all possible $A$. A significant $f_{b}(C)$ value means that all descendants $B$ of branch $b$ share alleles with $C$, which is more parsimoniously explained by an event of ancestral introgression from $C$ to $b$ (Malinsky et al. 2018). Using the inferred species tree, we determined all conformations $(\mathrm{A}, \mathrm{B} ; \mathrm{C}, \mathrm{O})$ needed to calculate $f_{b}(C)$ for all pairs of $C$ species and $b$ branches following Malinsky et al. (2018) with custom scripts (available at https://github.com/evochange) and R package treeman (1.1.3; Bennett et al. 2017). For each conformation, we calculated 'admixture proportion' $\left(f_{G}\right)$ as defined in Martin et al. (2015) and Malinsky et al. (2018) and z-scores with 1 Mb block jackknife approach following Malinsky et al. (2018). 'f-branch' values with Bonferroni-corrected $P \leq 0.05$ were considered significantly different from zero. We also calculated $f_{\text {hom }}$ (Martin et al. 2015) between blacktailed jackrabbits (P3) and several snowshoe hare populations (as P1 and P2) to evaluate levels of admixture estimated with $f_{b}(C)$ for this species pair (see Results and Discussion).

We also used $A B B A B A B A w i n d o w s . p y$ from genomics general to estimate the fraction of admixture $\left(f_{d}\right)$ (Martin et al. 2015) across $50 \mathrm{~kb}$ genomic sliding windows ( $\geq 100$ sites, $5 \mathrm{~kb}$ steps), to localize tracts of introgression in the genomes of northern latitude species. We performed three scans testing introgression between snowshoe hares (L. americanus) as P3 and Alaskan hares (L. othus), mountain hares (L. timidus) or white-tailed jackrabbits $(L$. townsendii) as alternative $\mathrm{P} 2$, using the Iberian hare (L. granatensis) as P1. Windows of top 


\section{Ferreira et al.}

$0.5 \% f_{d}$ were considered significant. Following Liu et al. (2015), we considered that significant windows in all three tests reflected introgression between snowshoe hares and the ancestral lineage of white-tailed jackrabbits/mountain hares/Alaskan hares, while significant windows in only one test result from recent introgression between the focal extant species. We obtained the annotation of genes in these windows from the European rabbit reference using biomaRt and used unique annotations to perform an enrichment analysis in $g$ :Profiler (accessed September 2019; Raudvere et al. 2019) using default parameters. We also calculated $\mathrm{d}_{\mathrm{xy}}$ for $f_{d}$ outlier windows and the exome-wide $\mathrm{d}_{\mathrm{xy}}$ distribution between the focal pair of P2-P3 species using popgenWindows.py from genomics general to calculate $\mathrm{d}_{\mathrm{xy}}$ in windows of $50 \mathrm{~kb}$ ( $\geq 2000$ sites, $5 \mathrm{~kb}$ steps).

\section{RESULTS}

\section{Whole Exome Sequencing Data}

Custom DNA captures showed high efficiency (32.3 average fold-enrichment) and specificity (average 10\% of sequenced bases off-target; Supplementary Table S2). Mapping cleaned reads onto species-specific pseudo-references resulted in an average target sequencing coverage of $16 \times(5-35 \times$ on average per sample; Supplementary Table S2) with 57.8 million genotyped sites per individual (Supplementary Table S2). Two lower coverage individuals (one hare individual and one pygmy rabbit individual) and one locality duplicate (one hare) were removed from the final dataset to maximize data quality and avoid geographic redundancy (Supplementary Table S1). Combining new and published data, all analyses were performed on a dataset of 15 hare species (32 individuals), one pygmy rabbit, and the European rabbit reference genome, unless otherwise noted (see Supplementary Table S1). 


\section{Introgression in Hares}

\section{Phylogenetic Relationships among Hares}

The overall topologies of the concatenated ML phylogeny $(11,949,529$ positions with no missing data) and the multispecies-coalescent species trees of ASTRAL ( 8,889 gene trees estimated from $50 \mathrm{~kb}$ genomic intervals; alignment lengths between $1 \mathrm{~kb}$ and $29 \mathrm{~kb}$ ) and SVDquartets (45,779 unlinked SNPs) were largely concordant (Supplementary Figs. S1, S2 and S3). Most branching relationships were highly supported in general (ASTRAL posterior probabilities = 1, SVDquartets bootstraps > 90; Fig. 1 and Supplementary Figs. S1, S2, S3 and S4) with most species recovered as monophyletic (Supplementary Figs. S1, S2a and S3a). The only exceptions involved very closely related species with disputed taxonomy, such as paraphyly of the mountain hare with the Alaskan hare, the broom hare (L. castroviejoi) with the Corsican hare (L. corsicanus) (Alves et al. 2008; Melo-Ferreira et al. 2012), or paraphyly among a lineage showing deep intraspecific divergence, the Cape hare (L. capensis), with the Ethiopian hare (L. fagani) (Lado et al. 2019) (Supplementary Figs. S1, S2 and S3 and Supplementary Tables S3 and S4).

Our two calibration strategies recovered overlapping $95 \%$ high posterior density (HPD) intervals of divergence times for relatively recent splits (e.g., diversification of Eurasian and African species; Supplementary Table S5), but the Lepus-based fossil calibrations suggested more recent ages for deeper nodes (Supplementary Table S5 and Fig. S5). For instance, the hare radiation was estimated at $~ 5.83$ million year ago (95\% HPD 6.17$5.34 \mathrm{Ma}$ ) using fossil calibrations outside Lepus, while Lepus fossil calibration sets it at $~ 4.05$ Ma (95\% HPD 5.00-3.18 Ma). All species tree analyses were consistent in showing that the deepest branching events involved North American species: white-sided jackrabbit, blacktailed jackrabbit, and snowshoe hare (Fig. 1b). In accordance, ancestral reconstruction of biogeographic distributions based on the best fitting DIVALIKE+J model supported a North America origin, with subsequent colonization of Eurasia (2.85 and 1.99 Ma for deeper and 


\section{Ferreira et al.}

Lepus-fossil calibration, respectively) and Africa (1.85 and 1.33 Ma) (Fig. 1c and

Supplementary Table S6). We also found support for one or more re-colonization events of North America from Eurasia, represented by white-tailed jackrabbits and Alaskan hares (Fig. 1 and Supplementary Fig. S6 and Table S7).

\section{Incomplete Lineage Sorting and Introgression}

We recovered a highly supported species tree across phylogenetic methods, albeit with considerable phylogenetic discordance among sequenced regions [average Robinson-Foulds (RF) pairwise distance between local trees was 0.73$]$. No local tree completely recovered the species tree topology (minimum RF distance between gene and species tree was 0.13) (Supplementary Fig. S7) and the majority rule consensus tree showed low internode certainty (Supplementary Fig. S8). Phylogenetic discordance was also apparent in the ASTRAL species tree with all but five branches showing quartet scores below 0.6 (Fig. 1b, Supplementary Figs. S2, S4 and Tables S8 and S9). The inference of a concordant species tree across ASTRAL and SVDquartets suggests that the low quartet scores are not highly impacted by gene tree estimation error (Molloy and Warnow 2018). Splits network analysis of individual gene trees also supported many alternative relationships (represented by cuboid structures connecting alternative topologies) particularly involving deeper branches (Fig. 2). We estimated similar levels of discordance between X-linked and autosomal genealogies and the inferred species trees (Supplementary Fig. S7). Furthermore, a species tree inferred with X-linked data differed from the genome-wide species tree and showed lower overall branch support (Supplementary Fig. S9 and Table S10). Nucleotide diversity was relatively low within species (0.13-0.63\%) and overlapped with estimates of absolute genetic divergence between species ( $\mathrm{d}_{\mathrm{xy}}$ 0.17-1.11\%; Supplementary Tables S3 and S4). However, these ranges reflect some taxonomic uncertainties. For example, some instances of low interspecific divergence 


\section{Introgression in Hares}

concern species with debated species-level status (e.g., the Corsican-broom hare and mountain-Alaskan hare complexes; Alves et al. 2008; Melo-Ferreira et al. 2012), while high diversity may reflect intraspecific cryptic divergence (e.g., snowshoe hares, Melo-Ferreira et al. 2014; Cape hares, Lado et al. 2019).

On average, $49 \%$ of heterozygous sites where shared between species (Supplementary Table S11). Considerable phylogenetic discordance among gene trees combined with such high levels of shared polymorphism between species could be explained by incomplete lineage sorting, secondary introgression, or a combination of both processes. We found that $88 \%$ of the minimum absolute D-statistics $\left(D_{\min }\right)($ Malinsky et al. 2018) for all trios of species in our dataset were significantly different from zero (Bonferroni-corrected $\mathrm{P}<0.05$; Supplementary Fig. S10), providing overwhelming support for gene flow either between extant species pairs or between ancestral lineages (Malinsky et al. 2018). Our inferences of the multispecies network coalescent implemented (Supplementary Fig. S11), ancestral population graph reconstruction (based on 30,709 biallelic SNVs; Supplementary Figs. S12 and S13), and estimates of admixture proportions among species based on the 'f-branch' metric $\left(f_{b}(C)\right)($ Fig. 3) were all consistent with recurrent gene flow between species layered across the diversification of Lepus. With $f b(C)$ (Fig. 3) and network analysis (Supplementary Figs. S11 and S12), we detected introgression among extant species pairs within all of the major geographic regions that are currently sympatric, suggesting ongoing or recent hybridization. For example, strong gene flow was found between black-tailed jackrabbits and snowshoe hares in North America $\left(f_{b}(C)=19 \% ; P=2.04 \mathrm{E}-169\right)$, or between European brown hares and mountain hares from Eurasia $\left(f_{b}(C)=18 \% ; P=1.73 \mathrm{E}-233\right.$; Fig. 3 and Supplementary Table S12). In general, we found decreased admixture proportions with increased genetic divergence between species, although this correlation was only significant when considering species with non-overlapping distributions (Fig. 4). Several species pairs 


\section{Ferreira et al.}

with current contact zones showed admixture even when genetic divergence was relatively high, such as snowshoe hares and black-tailed jackrabbits $\left(\mathrm{d}_{\mathrm{xy}}=0.97 \%\right.$; TMRCA $\sim 4.8 \mathrm{Ma}$, Supplementary Fig. S5 and Tables S4 and S5).

We also found evidence for introgression between ancestral populations, which has likely affected deeper branches of the species tree. These ancestral events were detected as network reticulations, as significant $f b(C)$ values among ancestral branches (y-axis in Fig. 3) or similar admixture levels shared among species within clades (x-axis in Fig. 3). We detect ancestral events of introgression connecting major clades within Eurasia (e.g., European hares and the ancestor of the mountain hare/Alaskan hare/white-tailed jackrabbit clade), African and Eurasian lineages (e.g., ancestral of all African species and the Corsican and broom hare ancestral), and Eurasian and North American lineages (e.g., snowshoe hares and the ancestral lineage of the mountain hare/Alaskan hare/white-tailed jackrabbit; Fig. 3, 4, Supplementary Figs. S11 and S12, and Table S12). Finally, we found significant introgression among species from different continents, such as North American hares and species from Africa and Western Europe (Fig. 3 and 4), which was also suggested by a network with two reticulations and by ancestral population graph reconstruction (Supplementary Figs. S11c and S12). These results suggest that introgression affected the very early branches of the Lepus radiation, and that the genetic legacy of these gene flow events persists in the gene pool of descendant species today (Fig. 3 and 4).

\section{Genes affected by Ancestral Introgression}

We consistently detected ancestral introgression between the ancestors of coat color changing species in our dataset: white-tailed jackrabbits, mountain hares, Alaskan hares, and snowshoe hares (Fig. 3 and Supplementary Fig. S11). Motivated by recent work showing that introgressive hybridization has shaped local adaptation in seasonal coat color changing 


\section{Introgression in Hares}

species (Jones et al. 2018, 2020a; Giska et al. 2019), we examined the contribution of gene flow to standing variation and local adaptation in these species. We detected 119 putative windows of ancient introgression across all major chromosomes, highlighting the genomewide contribution of ancestral introgression (Fig. 5; Supplementary Table S13). The $f_{d}$ outlier windows of ancestral introgression contained 54 annotated genes (Supplementary Table S14). This set of genes was enriched for the gene ontology term "E-Box binding" ( 3 of the 54 genes; Supplementary Table S15), a DNA motif found in the promoters of many genes, suggesting that genomic regions affected by ancient introgression may be enriched for transcription factors involved in trans-regulation of gene expression. Among these transcription factors we found the circadian clock related gene ARNTL2 (Sasaki et al. 2009) and pigmentation related gene TCF4 (Furumura et al. 2001; Le Pape et al. 2009) (Fig. 5). In addition, the list of 54 genes includes a gene involved in brown fat differentiation $(E B F 2$; Rajakumari et al. 2013), and a photoreceptor-related gene (PDE6H; Kohl et al. 2012).

\section{DISCUSSION}

We used phylogenetic analyses of whole exome data to tease apart signatures of stochastic lineage sorting and admixture across the evolutionary history of the Lepus radiation. By accounting for these sources of phylogenetic discordance, we were able to detect pervasive introgression across the evolution of this recent and rapid mammalian radiation. Below we discuss the biogeographic and evolutionary implications of our analyses, focusing on the long-term impacts of temporally layered hybridization in shaping patterns of shared genetic variation within and among extant species.

The Effect of Persistent Gene Flow on Phylogenetic Inference 


\section{Ferreira et al.}

We present a resolved genome-wide phylogeny for the genus Lepus despite extensive incomplete lineage sorting and pervasive gene flow. Our genome-wide analysis covered all major lineages across the worldwide range of hares, substantially extending previous analyses based on more limited genetic sampling (Halanych et al. 1999; Melo-Ferreira et al. 2012; Ge et al. 2013; Tolesa et al. 2017). A systematic evaluation of species limits and hare taxonomy is beyond the scope of our work, as it would require genome-wide data from an expanded inter and intraspecific sample. However, our sampling should not bias the estimated phylogenetic relationships and may even underestimate species diversity. Thus our inferences of shared variation across species are likely to be conservative.

To estimate species relationships, we combined species tree inferences that do not account for gene flow with network-based inferences that explicitly consider introgression. The resulting topologies were generally consistent between methods when considering up to three reticulations (Fig. 1 and Supplementary Fig. S11). However, there were limits to this approach. For example, the alternative placement of European, Corsican, and broom hares, as closer to the Eurasian or African Lepus clades depended on the number of reticulations considered (Supplementary Fig. S11). This uncertainty likely reflects long-term admixture among Eurasian and African lineages, including the European hare (Fig. 3 and Supplementary Fig. S11) whose range overlaps with species from both continents (Fig. 1a). Another example is the alternative sister relationship of snowshoe hares and black-tailed jackrabbits in the network with no reticulation (Supplementary Fig. S11), which could result from ancestral introgression between these species (see below). While an increased number of reticulation events could better represent the widespread gene flow uncovered in our work, allowing for more than three reticulations resulted in increased branch compression and therefore did not help resolve gene-to-gene incongruences (Supplementary Fig. S11; Yu and Nakhleh 2015; Wen et al. 2016). 


\section{Introgression in Hares}

We found that gene trees constructed from X-linked loci or autosome-linked loci showed similar levels of discordance with the exome-wide species tree (Supplementary Fig. S7). In general, the $\mathrm{X}$ chromosome could be expected to show less phylogenetic discordance due to its smaller effective population size and faster lineage sorting, and a tendency to accumulate hybrid incompatibilities (i.e., the large X-effect; Fontaine et al. 2015; Edelman et al. 2019; Li et al. 2019). Although there is evidence for reduced X-linked gene flow between some hybridizing European lineages (Seixas et al. 2018), very little is known about the genetic architecture of reproductive isolation between hare species. Moreover, less phylogenetic discordance of loci involved in reproductive isolation may not be always expected, particularly when speciation events are clustered in time (Wang and Hahn 2018) as is the case in Lepus (Supplementary Fig. S5).

\section{The Timing and Biogeography of the Lepus Radiation}

Our results suggest that the Lepus diversification followed major climatic shifts that occurred during the late Miocene, Pliocene and Pleistocene, similar to other terrestrial mammals (Simpson 1947; Ge et al. 2013). We inferred a North American origin between 5.83 Ma and 4.05 Ma [deeper or Lepus fossil calibrations, respectively, in agreement with Hibbard (1963), Halanych et al. (1999), Melo-Ferreira et al. (2012) and Ge et al. (2013)], coinciding with a global cold and dry period of the late Miocene that favored the expansion of grasslands worldwide (Osborne and Beerling 2006; Ge et al. 2013). The establishment of the Bering land bridges during late Pliocene and Pleistocene glacial periods (Simpson 1947; Hopkins 1959; Cook et al. 2016) may have allowed the subsequent colonization of Eurasia ( 2.77-1.99 Ma). Finally, we inferred secondary colonization of North America from Eurasia within the last 1 million years (Fig. 1 and Supplementary Figs. S5 and S6; Halanych et al. 1999), in agreement 


\section{Ferreira et al.}

with the Eurasia-North America exchange of cold-adapted fauna during Pleistocene glacial periods (Simpson 1947; Hoberg et al. 2012).

We note that our finding of pervasive introgression may distort aspects of these biogeographic inferences (Leaché et al. 2014; Solís-Lemus et al. 2016; Long and Kubatko 2018; Li et al. 2019; Jiao et al. 2020). If the inferred topology of the Lepus phylogeny is correct, as discussed above, then the general biogeographic reconstructions are probably robust. However, the timing of these events remains tentative given potential estimation bias caused by ancestral gene flow (Leaché et al. 2014; Li et al. 2019) and a lack of varied, independent, and reliable calibration points.

\section{The Legacy of Introgression during the Rapid Radiation of Hares}

Our inferences indicate that lineages often hybridized when they came into contact during the worldwide expansion of Lepus. Some of the inferred reticulation events overlap with known recent introgression, such as between mountain hares and European hares (Levänen et al. 2018) or between snowshoe hares and black-tailed jackrabbits (Jones et al. 2018, 2020a). However, our analysis also revealed prevailing signatures of deeper hybridization between ancestral populations, suggesting a persistent contribution of secondary introgression during the diversification of hares. These past hybridization events have resulted in extensive shared polymorphism among extant species (Fig. 3 and Supplementary Tables S11, S12 and Figs. S10, S11 and S12), with significant admixture still detected among species with non-overlapping distributions, even from different continents (Fig. 3 and Fig. 4).

Our analyses highlight how ancient gene flow can obscure accurate detection of contemporary hybridization. Similar to other systems (Malinsky et al. 2018; Edelman et al. 2019; Li et al. 2019), we estimated high levels of introgression based on D-statistics (e.g., $88 \%$ of $\mathrm{D}_{\min }$ values across all possible species trios were significant), but less reticulation 


\section{Introgression in Hares}

after taking phylogeny into account (e.g., 33\% of 'f-branch' statistics were significant). These findings suggest that phylogenetic correlation causes non-independence of summary-statistics and can thus lead to false pairwise inferences of gene flow between species (Eaton et al. 2015; Malinsky et al. 2018; Li et al. 2019). Given these results, signatures of hybridization among closely related species should be interpreted in the context of broader phylogenetic relationships whenever possible.

We also detected some discrepancies between the magnitude of gene flow inferred here and in previous works, which underscores the challenges of quantifying introgression across a reticulating radiation. For instance, we inferred substantial admixture proportions between black-tailed jackrabbits and snowshoe hares $\left(f_{b}(C)=19 \%\right.$, Fig. 3 and Supplementary Table S12). These estimates are one order of magnitude higher than recent studies suggesting that $2-3 \%$ of genomic variation in the Pacific Northwest snowshoe hare populations descends from hybridization with black-tailed jackrabbits in the last $~ 10,000$ generations (Jones et al. 2018, 2020a). Ancient introgression persisting in all snowshoe hare populations could reconcile this discrepancy. Indeed, we recovered consistent results $\left(f_{\text {hom }} \sim 3 \%\right)$ when we infer admixture proportions among black-tailed jackrabbits and different snowshoe hare populations (Supplementary Table S16), which likely reflects recent and geographically localized introgression. However, our estimates of overall admixture proportions between these species should be taken with caution as they depend on the accurate reconstruction of a short internal branch not fully supported across methods, and a species (snowshoe hare) that has been involved in multiple instances of introgression with different hare lineages (Fig. 3, 5 and Supplementary Table S12 and Fig. S11).

Introgression between species is often limited by purifying selection against hybrid incompatibilities (Schumer et al. 2018; Edelman et al. 2019), which agrees with the predominantly negative consequences of hybridization (Mayr 1963). Nonetheless, 


\section{Ferreira et al.}

hybridization is also expected to produce novel allelic combinations that increase phenotypic variation (Grant and Grant 2019; Marques et al. 2019). If coincident with ecological opportunity, introgressed variation could broadly facilitate adaptation (Grant and Grant 2019; Taylor and Larson 2019). Recent work has shown at least two instances where introgression between Lepus species has driven local adaptation (Jones et al. 2018; Giska et al. 2019), and standing introgressed variation may have contributed even more generally to adaptation during the radiation. We found that genetic variation introduced by ancient hybridization can persist through several speciation events (Fig. 3 and 4).

While much of large reservoir of shared variation may reflect stochastic sorting of neutral variation, some may have been maintained by selection (Guerrero and Hahn 2017; Jamie and Meier 2020) and helped facilitate colonization of the diverse habitats currently inhabited by hare species, from desert to arctic environments (Ge et al. 2013; Smith et al. 2018). In this respect, introgression between the ancestor of mountain hares/Alaskan hares/white-tailed jackrabbits and snowshoe hares (or an ancestral lineage) is particularly intriguing. These four species have adapted to highly seasonal environments through striking forms of phenotypic plasticity (e.g., seasonal coat color change; Mills et al. 2013; Zimova et al. 2018) that have been at least partially shaped by adaptive introgression at the Agouti pigmentation gene from non-color changing species (ASIP; Jones et al. 2018; Giska et al. 2019). Here we estimated that a pulse of ancient introgression occurred at least $0.71 \mathrm{Ma}$ (Lepus fossil calibration; Supplementary Fig. S5 available on Dryad) and affected genomic regions containing genes associated with circadian rhythm regulation (ARNTL2; Sasaki et al. 2009), pigmentation (TCF4; Furumura et al. 2001; Le Pape et al. 2009), thermoregulation (EBF2; Rajakumari et al. 2013) and visual perception (PDE6H; Kohl et al. 2012). While ASIP would also be a likely candidate for adaptive introgression between these lineages (Jones et 


\section{Introgression in Hares}

al. 2018), our exome sequencing coverage of this region was too sparse for detailed windowbased analysis.

The functions of these introgressed genes overlap with common physiological adaptations of northern latitude animals to seasonal conditions, such as higher metabolic rates, regulation of body temperature and non-shivering thermogenesis (Hart et al. 1965; Feist and Rosenmann 1975; Rogowitz 1990; Pyörnilä et al. 2008; Sheriff et al. 2009), seasonal camouflage (Grange 1932; Hewson 1958; Hansen and Bear 1963; Mills et al. 2018; Zimova et al. 2018), and visual acuity in response to dim winter light in northern latitudes (Stokkan et al. 2013). Furthermore, the functions of two of these genes, pigmentation and circadian rhythms, are linked to pathways activated during seasonal coat color changing molts (Ferreira et al. 2017, 2020). The functional relevance of these candidates to local adaptation must await further testing. Nonetheless, substantial introgression along the rapid diversification of a group of organisms, as we describe here, may bolster genetic variation within species and have a greater role in local adaptation than previously anticipated (Grant and Grant 2019; Taylor and Larson 2019). However, we also cannot exclude that some of these shared variants have been maintained by long-term balancing selection rather than secondary introgression (Supplementary Fig. S14; Smith and Kronforst 2013; Liu et al. 2015; Guerrero and Hahn 2017). Regardless of origin, the Lepus radiation provides an intriguing system by which to test the long-term evolutionary importance of shared genetic variation across a rapid radiation.

\section{SUPPlemEnTARY MATERIAL}

Raw sequence reads used in this article are available in the National Center for Biotechnology Information (NCBI) Sequence Read Archive (SRA) under accession numbers SRR12020579 to SRR12020510 and BioProject number PRJNA639005. Supplementary 


\section{Ferreira et al.}

materials, including data files and/or online-only appendices, can be found in the Dryad Digital Repository (doi:10.5061/dryad.bzkh18967). The pipeline and custom scripts used for this study are available at https://github.com/evochange.

\section{FUNDING}

Funding and support for this research was provided by Fundação para a Ciência e a Tecnologia (FCT) (project grant “CHANGE” - PTDC/BIA-EVF/1624/2014, Portuguese National Funds) and the National Science Foundation (NSF) (EPSCoR OIA-1736249 and DEB-1907022 grant). MSF was supported by POPH-QREN funds from ESF and Portuguese MCTES/FCT (PD/BD/108131/2015 PhD grant in the scope of BIODIV PhD programme at Faculty of Sciences, University of Porto), FCT (PTDC/BIA-EVF/1624/2014), and NSF (OIA1736249). MRJ was supported by an NSF Graduate Research Fellowship (DGE-1313190). JM-F was supported by an FCT CEEC contract (CEECIND/00372/2018). Instrumentation, laboratory, and computational support was provided by CIBIO NEWGEN sequencing platform, supported by European Union's Seventh Framework Program for research, technological development and demonstration under grant agreement no. 286431, by the University of Montana Genomics Core, supported by a grant from the M.J. Murdock Charitable Trust. A grant from the Eunice Kennedy Shriver National Institute of Child Health and Human Development (R01HD073439) supported the development of exome capture protocols that were utilized in the current study. Additional support was obtained from European Union's Horizon 2020 Research and Innovation Programme under grant Agreement Number 857251, the Laboratoire International Associé (LIA) “Biodiversity and Evolution” funded by InEE (CNRS, France) and FCT (Portugal), COMPETE2020, PORTUGAL2020, and ERDF (POCI-01-0145-FEDER-022184), and from Portugal-United States of America 


\section{Introgression in Hares}

Research Networks Program funds from Fundação Luso-Americana para o Desenvolvimento (FLAD) to PCA and MSF.

\section{ACKNOWLEDGEMENTS}

We thank Janet Rachlow, Gloria Portales, Armando Geraldes, José Carlos Brito, Jérôme Letty, Conrad Matthee, Alexei Kryukov, Ettore Randi, Christian Gortazar, Rafael Villafuerte, Fernando Ballesteros, Klaus Hackländer and Zbyszek Boratynski for assistance with sample collection. The Alaskan hare samples used in this work were generously provided by the University of Alaska Museum (voucher codes UAM42143 and UAM45545). We thank Fernando Seixas, Tiago Antão, Hannes Svardal, Nathaniel Edelman, the EVOCHANGE lab, the Good lab, and the UNVEIL network for helpful discussions on the generation and analysis of data.

\section{REFERENCES}

Alves P.C., Melo-Ferreira J., Branco M., Suchentrunk F., Ferrand N., Harris D.J. 2008.

Evidence for genetic similarity of two allopatric European hares (Lepus corsicanus and L. castroviejoi) inferred from nuclear DNA sequences. Mol. Phylogenet. Evol. 46:11917.

Árnason Ú., Lammers F., Kumar V., Nilsson M.A., Janke A. 2018. Whole-genome sequencing of the blue whale and other rorquals finds signatures for introgressive gene flow. Sci. Adv. 4.

Van der Auwera G.A., Carneiro M.O., Hartl C., Poplin R., del Angel G., Levy-Moonshine A., Jordan T., Shakir K., Roazen D., Thibault J., Banks E., Garimella K. V, Altshuler D., Gabriel S., DePristo M.A. 2013. From fastQ data to high-confidence variant calls: The genome analysis toolkit best practices pipeline. Curr. Protoc. Bioinforma. 11. 


\section{Ferreira et al.}

Barlow A., Cahill J.A., Hartmann S., Theunert C., Xenikoudakis G., Fortes G.G., Paijmans J.L.A., Rabeder G., Frischauf C., Grandal-d’Anglade A., García-Vázquez A., Murtskhvaladze M., Saarma U., Anijalg P., Skrbinšek T., Bertorelle G., Gasparian B., Bar-Oz G., Pinhasi R., Slatkin M., Dalén L., Shapiro B., Hofreiter M. 2018. Partial genomic survival of cave bears in living brown bears. Nat. Ecol. Evol. 2:1563-1570.

Barth J.M.I., Gubili C., Matschiner M., Tørresen O.K., Watanabe S., Egger B., Han Y.S., Feunteun E., Sommaruga R., Jehle R., Schabetsberger R. 2020. Stable species boundaries despite ten million years of hybridization in tropical eels. Nat. Commun. 11:1-13.

Bennett D.J., Sutton M.D., Turvey S.T. 2017. Treeman: An R package for efficient and intuitive manipulation of phylogenetic trees. BMC Res. Notes. 10:30.

Borowiec M.L. 2016. AMAS: A fast tool for alignment manipulation and computing of summary statistics. PeerJ. 2016:e1660.

Carneiro M., Rubin C.J., Palma F. Di, Albert F.W., Alföldi J., Barrio A.M., Pielberg G., Rafati N., Sayyab S., Turner-Maier J., Younis S., Afonso S., Aken B., Alves J.M., Barrell D., Bolet G., Boucher S., Burbano H.A., Campos R., Chang J.L., Duranthon V., Fontanesi L., Garreau H., Heiman D., Johnson J., Mage R.G., Peng Z., Queney G., Rogel-Gaillard C., Ruffier M., Searle S., Villafuerte R., Xiong A., Young S., ForsbergNilsson K., Good J.M., Lander E.S., Ferrand N., Lindblad-Toh K., Andersson L. 2014. Rabbit genome analysis reveals a polygenic basis for phenotypic change during domestication. Science. 345:1074-1079.

Chifman J., Kubatko L. 2014. Quartet inference from SNP data under the coalescent model. Bioinformatics. 30:3317-3324.

Cook J.A., Galbreath K.E., Bell K.C., Campbell M.L., Carrière S., Colella J.P., Dawson N.G., Dunnum J.L., Eckerlin R.P., Fedorov V., Greiman S.E., Haas G.M., Haukisalmi V., 


\section{Introgression in Hares}

Henttonen H., Hope A.G., Jackson D., Jung T.S., Koehler A. V, Kinsella J.M., Krejsa

D., Kutz S.J., Liphardt S., MacDonald S.O., Malaney J.L., Makarikov A., Martin J., McLean B.S., Mulders R., Nyamsuren B., Talbot S.L., Tkach V. V, Tsvetkova A., Toman H.M., Waltari E.C., Whitman J.S., Hoberg E.P., Cook J., Bell K., Colella J., Jackson D., Krejsa D., Liphardt S., McLean B., Galbreath K., Haas G., Toman H., Campbell M., Dunnum J., MacDonald S., Carrière S., Mulders R., Dawson N., Fedorov V., Greiman S., Jung T., Koehler A., Kinsella J., Kutz S., Malaney J., Makarikov A., Martin J., Nyamsuren B., Waltari Aaron E., Hoberg Animal E. 2016. The Beringian Coevolution Project: holistic collections of mammals and associated parasites reveal novel perspectives on evolutionary and environmental change in the North. Arct. Sci. 3:585-617.

Degnan J.H. 2018. Modeling Hybridization Under the Network Multispecies Coalescent. Syst. Biol. 67:786-799.

Durinck S., Moreau Y., Kasprzyk A., Davis S., De Moor B., Brazma A., Huber W. 2005. BioMart and Bioconductor: a powerful link between biological databases and microarray data analysis. Bioinformatics. 21:3439-3440.

Durinck S., Spellman P.T., Birney E., Huber W. 2009. Mapping identifiers for the integration of genomic datasets with the R/ Bioconductor package biomaRt. Nat. Protoc. 4:11841191.

Eaton D.A.R., Hipp A.L., González-Rodríguez A., Cavender-Bares J. 2015. Historical introgression among the American live oaks and the comparative nature of tests for introgression. Evolution. 69:2587-2601.

Edelman N.B., Frandsen P.B., Miyagi M., Clavijo B., Davey J., Dikow R.B., García-Accinelli G., Van Belleghem S.M., Patterson N., Neafsey D.E., Challis R., Kumar S., Moreira G.R.P., Salazar C., Chouteau M., Counterman B.A., Papa R., Blaxter M., Reed R.D., 


\section{Ferreira et al.}

Dasmahapatra K.K., Kronforst M., Joron M., Jiggins C.D., Owen McMillan W., Palma

F. Di, Blumberg A.J., Wakeley J., Jaffe D., Mallet J. 2019. Genomic architecture and introgression shape a butterfly radiation. Science. 366:594-599.

Feist D.D., Rosenmann M. 1975. Seasonal sympatho-adrenal and metabolic responses to cold in the Alaskan snowshoe hare (Lepus americanus macfarlani). Comp. Biochem. Physiol. -- Part A Physiol. 51:449-455.

Ferreira M.S., Alves P.C., Callahan C.M., Giska I., Farelo L., Jenny H., Mills L.S., Hackländer K., Good J.M., Melo- Ferreira J. 2020. Transcriptomic regulation of seasonal coat color change in hares. Ecol. Evol. 10:1180-1192.

Ferreira M.S., Alves P.C., Callahan C.M., Marques J.P., Mills L.S., Good J.M., Melo-Ferreira J. 2017. The transcriptional landscape of seasonal coat color molt in the snowshoe hare. Mol. Ecol. 26:4173-4185.

Fontaine M.C., Pease J.B., Steele A., Waterhouse R.M., Neafsey D.E., Sharakhov I. V, Jiang X., Hall A.B., Catteruccia F., Kakani E., Mitchell S.N., Wu Y.-C., Smith H.A., Love R.R., Lawniczak M.K., Slotman M.A., Emrich S.J., Hahn M.W., Besansky N.J. 2015. Extensive introgression in a malaria vector species complex revealed by phylogenomics.

Science. 347:1258522-1258522.

Furumura M., Potterf S.B., Toyofuku K., Matsunaga J., Muller J., Hearing V.J. 2001.

Involvement of ITF2 in the transcriptional regulation of melanogenic genes. J. Biol. Chem. 276:28147-54.

Ge D., Wen Z., Xia L., Zhang Z., Erbajeva M., Huang C., Yang Q. 2013. Evolutionary History of Lagomorphs in Response to Global Environmental Change. PLoS One. 8:e59668.

Giska I., Farelo L., Pimenta J., Seixas F.A., Ferreira M.S., Marques J.P., Miranda I., Letty J., Jenny H., Hackländer K., Magnussen E., Melo-Ferreira J. 2019. Introgression drives 


\section{Introgression in Hares}

repeated evolution of winter coat color polymorphism in hares. Proc. Natl. Acad. Sci. 116:24150-24156.

Gittelman R.M., Schraiber J.G., Vernot B., Mikacenic C., Wurfel M.M., Akey J.M. 2016.

Archaic Hominin Admixture Facilitated Adaptation to Out-of-Africa Environments. Curr. Biol. 26:1-8.

Grange W.B. 1932. The Pelages and Color Changes of the Snowshoe Hare, Lepus americanus phaeonotus, Allen. J. Mammal. 13:99.

Grant P.R., Grant B.R. 2019. Hybridization increases population variation during adaptive radiation. Proc. Natl. Acad. Sci. 116:23216-23224.

Green R.E., Krause J., Briggs A.W., Maricic T., Stenzel U., Kircher M., Patterson N., Li H., Zhai W., Fritz M.H.-Y., Hansen N.F., Durand E.Y., Malaspinas A.-S., Jensen J.D., Marques-Bonet T., Alkan C., Prüfer K., Meyer M., Burbano H.A., Good J.M., Schultz R., Aximu-Petri A., Butthof A., Höber B., Höffner B., Siegemund M., Weihmann A., Nusbaum C., Lander E.S., Russ C., Novod N., Affourtit J., Egholm M., Verna C., Rudan P., Brajkovic D., Kucan Ž., Gušic I., Doronichev V.B., Golovanova L. V, Lalueza-Fox C., de la Rasilla M., Fortea J., Rosas A., Schmitz R.W., Johnson P.L.F., Eichler E.E., Falush D., Birney E., Mullikin J.C., Slatkin M., Nielsen R., Kelso J., Lachmann M., Reich D., Pääbo S. 2010. A draft sequence of the Neandertal genome. Science. 328:710 722.

Guerrero R.F., Hahn M.W. 2017. Speciation as a sieve for ancestral polymorphism. Mol. Ecol. 26:5362-5368.

Halanych K.M., Demboski J.R., van Vuuren B.J., Klein D.R., Cook J. a. 1999. Cytochrome b phylogeny of North American hares and jackrabbits (Lepus, Lagomorpha) and the effects of saturation in outgroup taxa. Mol. Phylogenet. Evol. 11:213-221.

Hansen R.M., Bear G.D. 1963. Winter coats of white-tailed jackrabbits in southwestern 


\section{Ferreira et al.}

Colorado. J. Mammology. 44:420-422.

Hart J.S., Pohl H., Tener J.S. 1965. Seasonal acclimatization in varying hare (Lepus americanus). Can. J. Zool. 43:731-744.

Hewson R. 1958. Moults and winter whitening in the mountain hare Lepus timidus scoticus, Hilzheimer. Proc. Zool. Soc. London. 131:99-108.

Hibbard C. 1963. The Origin of the P 3 Pattern of Sylvilagus, Caprolagus, Oryctolagus and Lepus. J. Mammal. 44:1-15.

Hoberg E.P., Galbreath K.E., Cook J.A., Kutz S.J., Polley L. 2012. Northern Host-Parasite Assemblages. History and Biogeography on the Borderlands of Episodic Climate and Environmental Transition. Advances in Parasitology. Academic Press. p. 1-97.

Hopkins D.M. 1959. Cenozoic history of the Bering land bridge. Science. 129:1519-1528.

Huson D.H., Bryant D. 2006. Application of phylogenetic networks in evolutionary studies. Mol. Biol. Evol. 23:254-267.

Inoue J., Donoghue P.C.J., Yang Z. 2010. The Impact of the Representation of Fossil Calibrations on Bayesian Estimation of Species Divergence Times. Syst. Biol. 59:74-89. Jamie G.A., Meier J.I. 2020. The Persistence of Polymorphisms across Species Radiations. Trends Ecol. Evol. 35:795-808.

Jiao X., Flouri T., Rannala B., Yang A.Z. 2020. The Impact of Cross-Species Gene Flow on Species Tree Estimation. Syst. Biol. 0:1-18.

Jones M.R., Mills L.S., Alves P.C., Callahan C.M., Alves J.M., Lafferty D.J.R., Jiggins F.M., Jensen J.D., Melo-Ferreira J., Good J.M. 2018. Adaptive introgression underlies polymorphic seasonal camouflage in snowshoe hares. Science. 360:1355-1358.

Jones M.R., Mills L.S., Jensen J.D., Good J.M. 2020a. The origin and spread of locally adaptive seasonal camouflage in snowshoe hares. Am. Nat. 196:316-332.

Jones M.R., Mills L.S., Jensen J.D., Good J.M. 2020b. Convergent evolution of seasonal 


\section{Introgression in Hares}

camouflage in response to reduced snow cover across the snowshoe hare range.

Evolution. 74:2033-2045.

Kinoshita G., Nunome M., Kryukov A.P., Kartavtseva I. V., Han S.-H., Yamada F., Suzuki

H. 2019. Contrasting phylogeographic histories between the continent and islands of

East Asia: Massive mitochondrial introgression and long-term isolation of hares

(Lagomorpha: Lepus). Mol. Phylogenet. Evol. 136:65-75.

Kobert K., Salichos L., Rokas A., Stamatakis A. 2016. Computing the Internode Certainty and Related Measures from Partial Gene Trees. Mol. Biol. Evol. 33:1606-1617.

Kohl S., Coppieters F., Meire F., Schaich S., Roosing S., Brennenstuhl C., Bolz S., van Genderen M.M., Riemslag F.C.C., Lukowski R., den Hollander A.I., Cremers F.P.M., De Baere E., Hoyng C.B., Wissinger B. 2012. A Nonsense Mutation in PDE6H Causes Autosomal-Recessive Incomplete Achromatopsia. Am. J. Hum. Genet. 91:527-532.

Kozak K.M., McMillan O., Joron M., Jiggins C.D. 2018. Genome-wide admixture is common across the Heliconius radiation. bioRxiv. 414201.

Lado S., Alves P.C., Islam M.Z., Brito J.C., Melo-Ferreira J. 2019. The evolutionary history of the Cape hare (Lepus capensis sensu lato): insights for systematics and biogeography. Heredity. 123:634-646.

Lamichhaney S., Berglund J., Almén M.S., Maqbool K., Grabherr M., Martinez-Barrio A., Promerová M., Rubin C.-J., Wang C., Zamani N., Grant B.R., Grant P.R., Webster M.T., Andersson L. 2015. Evolution of Darwin's finches and their beaks revealed by genome sequencing. Nature. 518:371-375.

Landis M.J., Matzke N.J., Moore B.R., Huelsenbeck J.P. 2013. Bayesian analysis of biogeography when the number of areas is large. Syst. Biol. 62:789-804.

Leaché A.D., Harris R.B., Rannala B., Yang Z. 2014. The Influence of Gene Flow on Species Tree Estimation: A Simulation Study. Syst. Biol. 63:17-30. 


\section{Ferreira et al.}

Levänen R., Thulin C.-G., Spong G., Pohjoismäki J.L.O. 2018. Widespread introgression of mountain hare genes into Fennoscandian brown hare populations. PLoS One. 13:e0191790.

Li G., Figueiró H. V, Eizirik E., Murphy W.J., Yoder A. 2019. Recombination-Aware Phylogenomics Reveals the Structured Genomic Landscape of Hybridizing Cat Species. Mol. Biol. Evol. 36:2111-2126.

Li H. 2011. A statistical framework for SNP calling, mutation discovery, association mapping and population genetical parameter estimation from sequencing data. Bioinformatics. 27:2987-2993.

Li H. 2013. Aligning sequence reads, clone sequences and assembly contigs with BWAMEM. arXiv Prepr. arXiv:1303.

Li H., Handsaker B., Wysoker A., Fennell T., Ruan J., Homer N., Marth G., Abecasis G., Durbin R. 2009. The Sequence Alignment/Map format and SAMtools. Bioinformatics. 25:2078-9.

Liu J., Yu L., Arnold M.L., Wu C.-H., Wu S.-F., Lu X., Zhang Y.-P. 2011. Reticulate evolution: frequent introgressive hybridization among chinese hares (genus Lepus) revealed by analyses of multiple mitochondrial and nuclear DNA loci. BMC Evol. Biol. 11:223.

Liu K.J., Steinberg E., Yozzo A., Song Y., Kohn M.H., Nakhleh L. 2015. Interspecific introgressive origin of genomic diversity in the house mouse. 112:196-201.

Long C., Kubatko L. 2018. The Effect of Gene Flow on Coalescent-based Species-Tree Inference. Syst. Biol. 67:770-785.

Lopez-Martinez N. 2008. The lagomorph fossil record and the origin of the European rabbit. In: Alves P.C., Ferrand N., Häcklander K., editors. Lagomorph Biology: Evolution, Ecology and Conservation. Verlag Berlin Heidelberg: Springer. p. 27-46. 


\section{Introgression in Hares}

Malinsky M., Svardal H., Tyers A.M., Miska E.A., Genner M.J., Turner G.F., Durbin R. 2018. Whole-genome sequences of Malawi cichlids reveal multiple radiations interconnected by gene flow. Nat. Ecol. Evol. 2:1940-1955.

Marques D.A., Meier J.I., Seehausen O. 2019. A Combinatorial View on Speciation and Adaptive Radiation. Trends Ecol. Evol. 34:531-544.

Marques J.P., Seixas F.A., Farelo L., Callahan C.M., Good J.M., Montgomery W.I., Reid N., Alves P.C., Boursot P., Melo-Ferreira J. 2020. An Annotated Draft Genome of the Mountain Hare (Lepus timidus). Genome Biol. Evol. 12:3656-3662.

Martin S.H., Davey J.W., Jiggins C.D. 2015. Evaluating the use of ABBA-BABA statistics to locate introgressed loci. Mol. Biol. Evol. 32:244-257.

Matthee C., Van Vuuren B., Bell D., Robinson T. 2004. A Molecular Supermatrix of the Rabbits and Hares (Leporidae) Allows for the Identification of Five Intercontinental Exchanges During the Miocene. Syst. Biol. 53:433-447.

Matzke N.J. 2013. Probabilistic historical biogeography: new models for founder-event speciation, imperfect detection, and fossils allow improved accuracy and model-testing. Front. Biogeogr. 5.

Matzke N.J. 2014a. BioGeoBEARS: BioGeography with Bayesian (and likelihood) Evolutionary Analysis with R Scripts. Version 1.1.2. .

Matzke N.J. 2014b. Model selection in historical biogeography reveals that founder-event speciation is a crucial process in island clades. Syst. Biol. 63:951-970.

Mayr E. 1963. Animal species and evolution. Eugen. Rev. 55:226-228.

Meier J.I., Marques D.A., Mwaiko S., Wagner C.E., Excoffier L., Seehausen O. 2017. Ancient hybridization fuels rapid cichlid fish adaptive radiations. Nat. Commun. $8: 14363$.

Melo-Ferreira J., Alves P.C. 2018. Systematics of lagomorphs. In: Smith A., Alves P.C., 


\section{Ferreira et al.}

Häcklander K., editors. Lagomorphs: pikas, rabbits, and hares of the World. John Hopkins University Press. p. 9-12.

Melo-Ferreira J., Boursot P., Carneiro M., Esteves P.J., Farelo L., Alves P.C. 2012. Recurrent introgression of mitochondrial DNA among hares (Lepus spp.) revealed by species-tree inference and coalescent simulations. Syst. Biol. 61:367-381.

Melo-Ferreira J., Seixas F.A., Cheng E., Mills L.S., Alves P.C. 2014. The hidden history of the snowshoe hare, Lepus americanus: extensive mitochondrial DNA introgression inferred from multilocus genetic variation. Mol. Ecol.:4617-4630.

Meyer M., Kircher M. 2010. Illumina Sequencing Library Preparation for Highly Multiplexed Target Capture and Sequencing. Cold Spring Harb. Protoc. 2010.

Mills L.S., Bragina E., Kumar A. V., Zimova M., Feltner J., Davis B., Lafferty D., Häcklander K., Alves P.C., Good J.M., Melo-Ferreira J., Abramov A., Lopatina N., Fay K. 2018. Winter coat color polymorphisms identify global hotspots for evolutionary rescue from climate change. Science. 359:1033-1036.

Mills L.S., Zimova M., Oyler J., Running S., Abatzoglou J.T., Lukacs P.M. 2013. Camouflage mismatch in seasonal coat color due to decreased snow duration. Proc. Natl. Acad. Sci. U. S. A. 110:7360-7365.

Molloy E.K., Warnow T. 2018. To Include or Not to Include: The Impact of Gene Filtering on Species Tree Estimation Methods. Syst. Biol. 67:285-303.

Osborne C.P., Beerling D.J. 2006. Nature's green revolution: the remarkable evolutionary rise of C 4 plants. Philos. Trans. R. Soc. B Biol. Sci. 361:173-194.

Page A.J., Taylor B., Delaney A.J., Soares J., Seemann T., Keane J.A., Harris S.R. 2016. SNP-sites: rapid efficient extraction of SNPs from multi-FASTA alignments. Microb. genomics. 2:e000056.

Le Pape E., Passeron T., Giubellino A., Valencia J.C., Wolber R., Hearing V.J. 2009. 


\section{Introgression in Hares}

Microarray analysis sheds light on the dedifferentiating role of agouti signal protein in murine melanocytes via the Mc1r. Proc. Natl. Acad. Sci. U. S. A. 106:1802-1807.

Paradis E., Claude J., Strimmer K. 2004. APE: Analyses of Phylogenetics and Evolution in R language. Bioinformatics. 20:289-290.

Pease J.B., Hahn M.W. 2015. Detection and Polarization of Introgression in a Five-Taxon Phylogeny. Syst. Biol. 64:651-662.

Pickrell J.K., Pritchard J.K. 2012. Inference of Population Splits and Mixtures from GenomeWide Allele Frequency Data. PLoS Genet. 8:e1002967.

Pyörnilä A., Putaala A., Hissa R., Sulkava S. 2008. Adaptations to environment in the mountain hare (Lepus timidus): thermal physiology and histochemical properties of locomotory muscles. Can. J. Zool. 70:1325-1330.

Quinlan A.R., Hall I.M. 2010. BEDTools: a flexible suite of utilities for comparing genomic features. Bioinformatics. 26:841-842.

Rajakumari S., Wu J., Ishibashi J., Lim H.-W., Giang A.-H., Won K.-J., Reed R.R., Seale P. 2013. EBF2 Determines and Maintains Brown Adipocyte Identity. Cell Metab. 17:562574.

Raudvere U., Kolberg L., Kuzmin I., Arak T., Adler P., Peterson H., Vilo J. 2019. g:Profiler: a web server for functional enrichment analysis and conversions of gene lists (2019 update). Nucleic Acids Res. 47:191-198.

Ree R.H., Smith S.A. 2008. Maximum Likelihood Inference of Geographic Range Evolution by Dispersal, Local Extinction, and Cladogenesis. Syst. Biol. 57:4-14.

Reich D., Thangaraj K., Patterson N., Price A.L., Singh L. 2009. Reconstructing Indian population history. Nature. 461:489-494.

dos Reis M., Yang Z. 2011. Approximate Likelihood Calculation on a Phylogeny for Bayesian Estimation of Divergence Times. Mol. Biol. Evol. 28:2161-2172. 


\section{Ferreira et al.}

dos Reis M., Yang Z. 2019. Bayesian Molecular Clock Dating Using Genome-Scale Datasets.

In: Anisimova M., editor. Evolutionary Genomics. New York, NY: Springer New York. p. 309-330.

Robinson T.J., Yang F., Harrison W.R. 2002. Chromosome painting refines the history of genome evolution in hares and rabbits (order Lagomorpha). Cytogenet. Genome Res. 96:223-227.

Rogowitz G.L. 1990. Seasonal Energetics of the White-Tailed Jackrabbit (Lepus townsendii). J. Mammal. 71:277-285.

Ronquist F. 1997. Dispersal-vicariance analysis: A new approach to the quantification of historical biogeography. Syst. Biol. 46:195-203.

Salichos L., Rokas A. 2013. Inferring ancient divergences requires genes with strong phylogenetic signals. Nature. 497:327-331.

Salichos L., Stamatakis A., Rokas A. 2014. Novel information theory-based measures for quantifying incongruence among phylogenetic trees. Mol. Biol. Evol. 31:1261-1271.

Sambrook E., Fritsch F., Maniatis T. 1989. Molecular cloning. Cold Spring Harbour, NY: Cold Spring Harbour Press.

Sarver B.A.J., Keeble S., Cosart T., Tucker P.K., Dean M.D., Good J.M. 2017. Phylogenomic Insights into Mouse Evolution Using a Pseudoreference Approach. Genome Biol. Evol. 9:726-739.

Sasaki M., Yoshitane H., Du N.-H., Okano T., Fukada Y. 2009. Preferential Inhibition of BMAL2-CLOCK Activity by PER2 Reemphasizes Its Negative Role and a Positive Role of BMAL2 in the Circadian Transcription. J. Biol. Chem. 284:25149-25159.

Sayyari E., Whitfield J.B., Mirarab S. 2018. DiscoVista: Interpretable visualizations of gene tree discordance. Mol. Phylogenet. Evol. 122:110-115.

Schliep K.P. 2011. phangorn: phylogenetic analysis in R. Bioinform. 27:592-593. 


\section{Introgression in Hares}

Schumer M., Xu C., Powell D.L., Durvasula A., Skov L., Holland C., Blazier J.C.,

Sankararaman S., Andolfatto P., Rosenthal G.G., Przeworski M. 2018. Natural selection interacts with recombination to shape the evolution of hybrid genomes. Science. $360: 656-660$.

Seixas F.A., Boursot P., Melo-Ferreira J. 2018. The genomic impact of historical hybridization with massive mitochondrial DNA introgression. Genome Biol. 19:91.

Sheriff M.J., Kuchel L., Boutin S., Humphries M.M. 2009. Seasonal Metabolic Acclimatization in a Northern Population of Free-Ranging Snowshoe Hares, Lepus americanus. J. Mammal. 90:761-767.

Simpson G.G. 1947. Holarctic mammalian faunas and continental relationships during the cenozoic. Bull. Geol. Soc. Am. 58:613-688.

Smith A.T., Johnston C.H., Alves P.C., Häcklander K. 2018. Lagomorphs: Pikas, Rabbits and Hares of the World. Baltimore: Johns Hopkins University Press.

Smith J., Kronforst M.R. 2013. Do Heliconius butterfly species exchange mimicry alleles? Biol. Lett. 9:20130503-20130503.

Solís-Lemus C., Bastide P., Ané C. 2017. PhyloNetworks: A Package for Phylogenetic Networks. Mol. Biol. Evol. 34:3292-3298.

Solís-Lemus C., Yang M., Ané C. 2016. Inconsistency of Species Tree Methods under Gene Flow. Syst. Biol. 65:843-851.

Stamatakis A. 2018. RAxML version 8: a tool for phylogenetic analysis and post-analysis of large phylogenies. Bioinformatics. 30:1312-1313.

Stokkan K.-A., Folkow L., Dukes J., Neveu M., Hogg C., Siefken S., Dakin S.C., Jeffery G. 2013. Shifting mirrors: adaptive changes in retinal reflections to winter darkness in Arctic reindeer. Proc. R. Soc. B Biol. Sci. 280:20132451.

Svardal H., Quah F.X., Malinsky M., Ngatunga B.P., Miska E.A., Salzburger W., Genner 


\section{Ferreira et al.}

M.J., Turner G.F., Durbin R. 2020. Ancestral Hybridization Facilitated Species

Diversification in the Lake Malawi Cichlid Fish Adaptive Radiation. Mol. Biol. Evol. $37: 1100-1113$.

Swofford D.L. 2003. PAUP*. Phylogenetic Analysis Using Parsimony (* and Other Methods). .

Taylor S.A., Larson E.L. 2019. Insights from genomes into the evolutionary importance and prevalence of hybridization in nature. Nat. Ecol. Evol. 3:170-177.

Than C., Degnan J.H., Nakhleh L. 2011. Coalescent Histories on Phylogenetic Networks and Detection of Hybridization Despite Incomplete Lineage Sorting. Syst. Biol. 60:138-149.

Tolesa Z., Bekele E., Tesfaye K., Ben Slimen H., Valqui J., Getahun A., Hartl G.B., Suchentrunk F. 2017. Mitochondrial and nuclear DNA reveals reticulate evolution in hares (Lepus spp., Lagomorpha, Mammalia) from Ethiopia. PLoS One. 12:e0180137. Vanderpool D., Minh B.Q., Lanfear R., Hughes D., Murali S., Harris R.A., Raveendran M., Muzny D.M., Gibbs R.A., Worley K.C., Rogers J., Hahn M.W. 2020. Primate phylogenomics uncovers multiple rapid radiatio. bioRxiv. 043786.

Wang R.J., Hahn M.W. 2018. Speciation genes are more likely to have discordant gene trees. Evol. Lett. 2:281-296.

Wen D., Yu Y., Hahn M.W., Nakhleh L. 2016. Reticulate evolutionary history and extensive introgression in mosquito species revealed by phylogenetic network analysis. Mol. Ecol. 25:2361-2372.

White J.A. 1991. North American Leporinae (Mammalia: Lagomorpha) from late Miocene (Clarendonian) to latest Pliocene (Blancan). J. Vertebr. Paleontol. 11:67-89.

Yamada F., Takaki M., Suzuki H. 2002. Molecular phylogeny of Japanese Leporidae, the Amami rabbit Pentalagus furnessi, the Japanese hare Lepus brachyurus, and the mountain hare Lepus timidus, inferred from mitochondrial DNA sequences. Genes 


\section{Introgression in Hares}

Genet. Syst. 77:107-16.

Yang Z. 2007. PAML 4: Phylogenetic analysis by maximum likelihood. Mol. Biol. Evol. 24:1586-1591.

Yu Y., Degnan J.H., Nakhleh L. 2012. The Probability of a Gene Tree Topology within a Phylogenetic Network with Applications to Hybridization Detection. PLoS Genet. 8:1002660.

Yu Y., Dong J., Liu K.J., Nakhleh L. 2014. Maximum likelihood inference of reticulate evolutionary histories. Proc. Natl. Acad. Sci. 111:16448-16453.

Yu Y., Nakhleh L. 2015. A maximum pseudo-likelihood approach for phylogenetic networks. BMC Genomics. 16:S10.

Zhang C., Rabiee M., Sayyari E., Mirarab S. 2018. ASTRAL-III: Polynomial time species tree reconstruction from partially resolved gene trees. BMC Bioinformatics. 19:153.

Zimova M., Hackländer K., Good J.M., Melo-Ferreira J., Alves P.C., Mills L.S. 2018. Function and underlying mechanisms of seasonal colour moulting in mammals and birds: what keeps them changing in a warming world? Biol. Rev. 93:1478-1498. 


\section{FigURE LEGENDS}

Fig. 1 - Hare (Lepus spp.) evolutionary history and biogeography. (a) The distribution of the 15 hare species studied in this work obtained from the IUCN database (http://www.iucnredlist.org); (b) Coalescent species tree estimated with ASTRAL assigning individuals to species groups ( $\mathrm{n}>1$ except for the white-sided jackrabbit); (c) Ancestral range reconstruction under the DIVALIKE+J model implemented in BioGeoBEARS on the divergence time tree estimated with MCMCtree and calibrated with deep fossil calibration points. Pie charts represent the probability of each potential range, and squares represent the current range of extant taxa. Node labels represent estimated divergence times in millions of years. Confident intervals, an alternative biogeographic reconstruction based on Lepus fossil calibrations and ancestral ranges for the shoulders of the tree are provided in Supplementary Material.

Fig. 2 - The hare (Lepus spp.) species tree is underlined by extensive gene tree incongruence. Split network constructed from 8889 gene trees (5\% threshold) shows discordance among the gene tree topologies (cuboid structures represent alternative topologies) in deeper nodes of the species tree. Species are marked in accordance with the continents where they are distributed.

Fig. 3 - Admixture events are distributed across the hare (Lepus spp.) species tree. The 'f-branch' statistic $f_{b}(C)$ represents excess allele sharing between branches $b$ (y-axis) and $C$ (x-axis) of the species tree in Figure $1 \mathrm{~b}$. The gradient represents the $f_{b}(C)$ score, dark gray represents tests not consistent with the species tree (for each branch $b$, having itself or a sister taxon as donor $\mathrm{C}$ ) and asterisks denote block jackknifing significance at $P \leq 0.05$ (after 


\section{Introgression in Hares}

Bonferroni correction). Tips of the tree are marked according to their current distribution, and ancestral tips (dashed lines and labeled with letters) are marked according to the ancestral range reconstruction in Figure 1c (two colors represent the inference of two ranges with equivalent ( 0.5) probability). Ancestral tips are labeled from A to L corresponding to labels in Supplementary Table S11 available on Dryad.

\section{Fig. 4 - Admixture proportions decrease with genetic divergence between allopatric} species. We plot the 'f-branch' $\left(f_{b}(C)\right)$ values against exome-wide divergence $\left(\mathrm{d}_{\mathrm{xy}}\right)$ for extant species pairs, differentiating species with overlapping (sympatric/parapatric) or nonoverlapping (allopatric) distributions. The tendency line represents a linear regression relating $\mathrm{d}_{\mathrm{xy}}$ and all (significant and non-significant) $f_{b}(C)$ values calculated with function $\operatorname{lm}()$ in $\mathrm{R}$.

\section{Fig. 5 - The impact of ancestral introgression on extant northern latitude species. (a)}

Events of past and recent admixture inferred in this study involving snowshoe, Alaskan hares, mountain hares and white-tailed jackrabbits. The arrow indicates the direction of ancestral introgression inferred by PhyloNet and 'f-branch' and dashed lines indicate recent introgression inferred with 'f-branch'. Values above the lines represent admixture proportion (f) estimated with 'f-branch' or inheritance probability (IP) estimated with PhyloNet; (b) Genomic distribution of ancestral blocks of introgression (circles) inferred as shared outlier windows among fraction of admixture $\left(f_{d}\right)$ analysis testing for admixture among snowshoe hares and each one of the three other northern latitude species. Tests were run in $50 \mathrm{~kb}$ genomic sliding windows, and outlier windows are in the top $0.5 \%$ of the $f_{d}$ distribution. 
a)

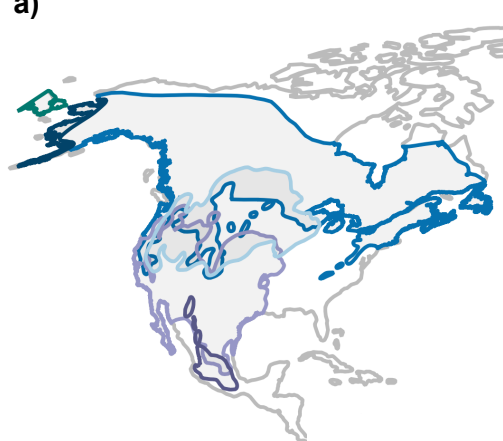

North America

-Alaskan hare

- Snowshoe hare

-White-tailed jackrabbit

-Black-tailed jackrabbit

—White-sided jackrabbit

b)

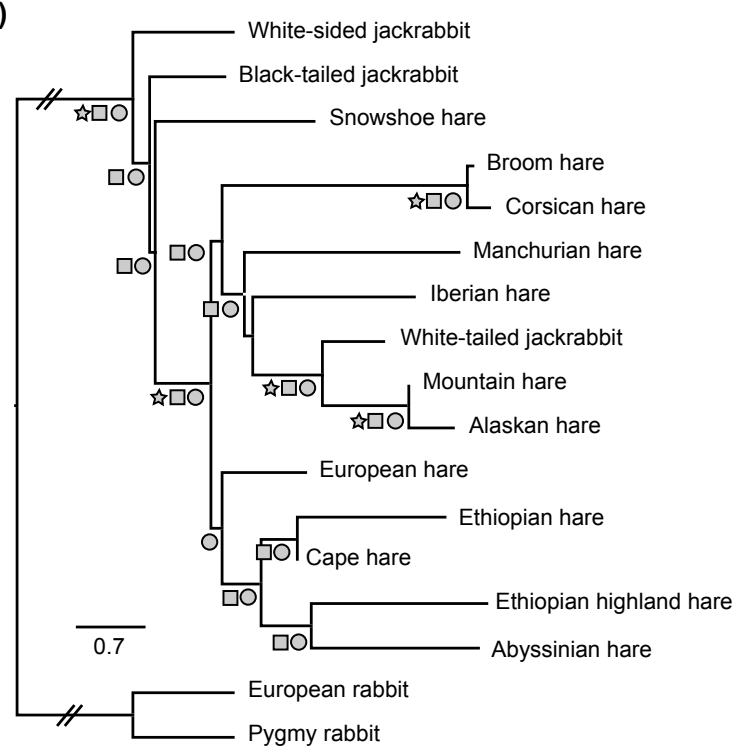

Systematic Biology

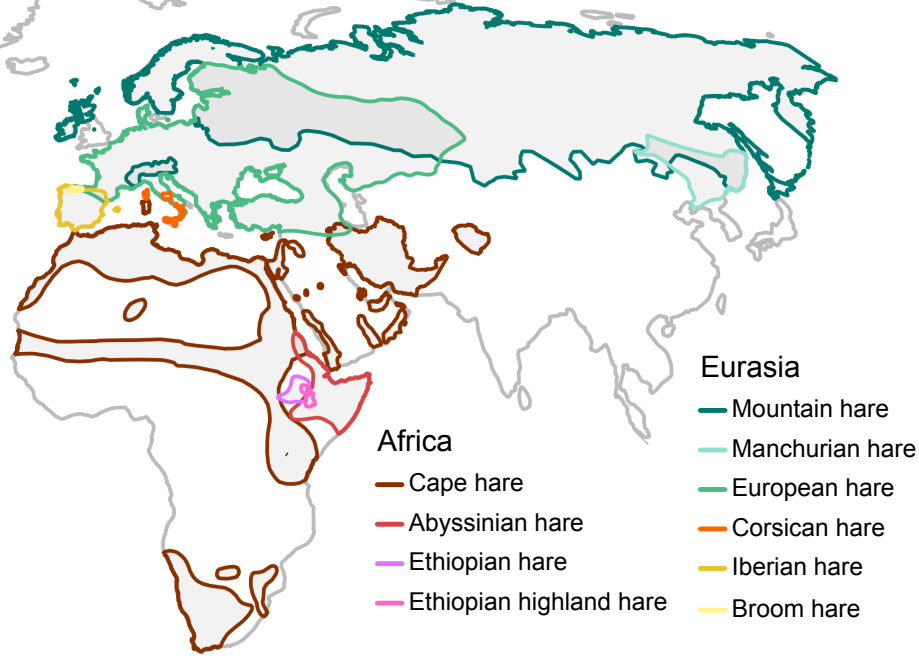

c)

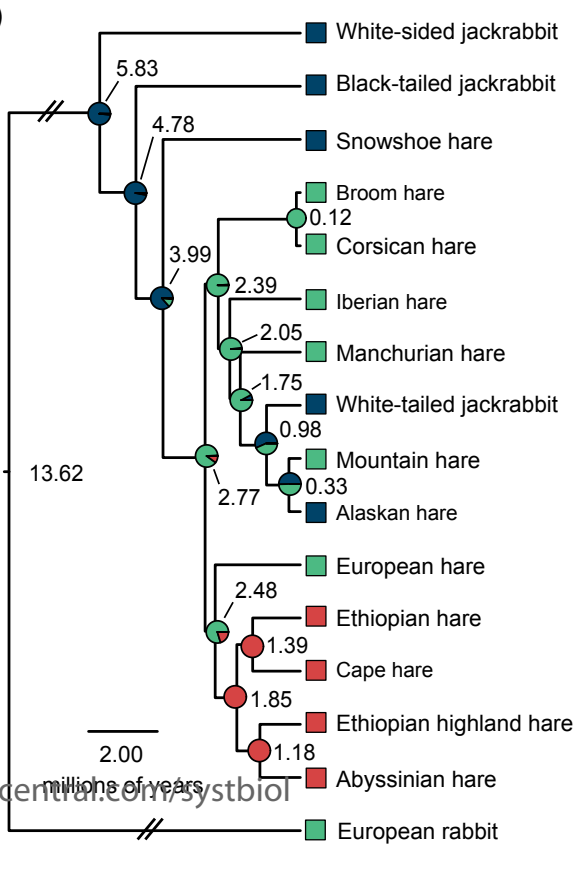

North Am 


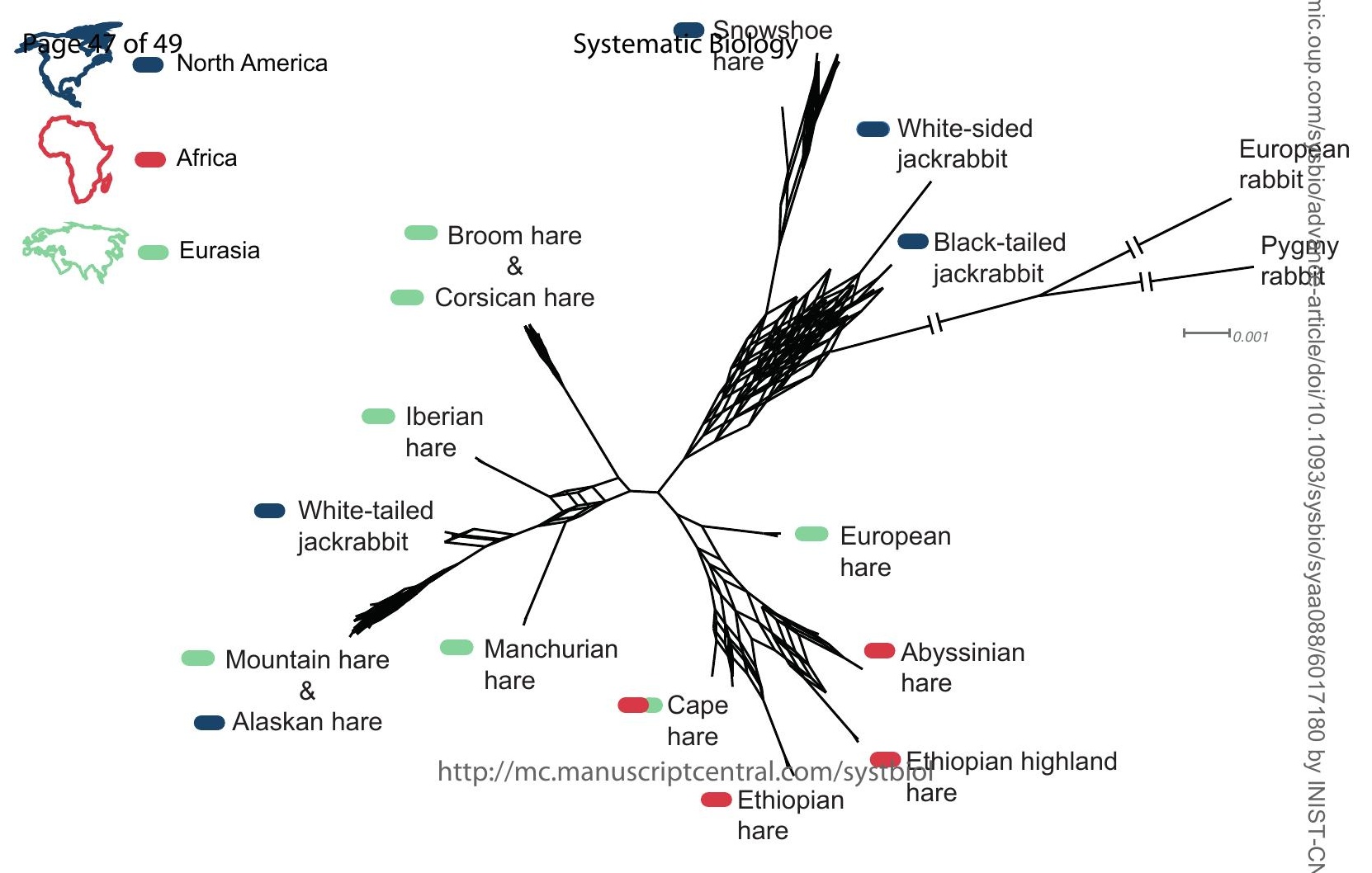




\section{$f_{b}(C)$}

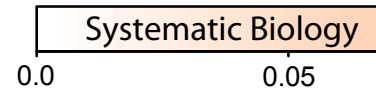

0.05

0.1

Page 48 of 49

White-sided jackrabbit Black-tailed jackrabbit

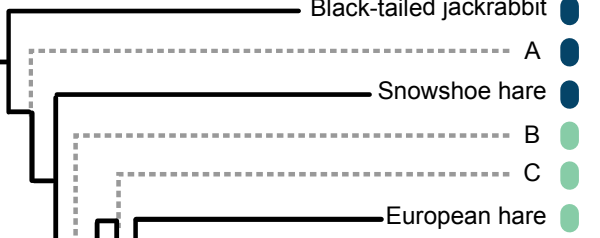

\begin{tabular}{|c|c|c|c|c|c|c|c|c|c|c|c|c|c|c|}
\hline & & & & & & & & & & & & & & ¿ \\
\hline & & & & & & & & & & & & & & $\widehat{\bar{d}}$ \\
\hline & & & & & & & & & & & & & $\star$ & $\stackrel{0}{2}$ \\
\hline & & & & & & & & & & & & & & 3 \\
\hline & & & & & & & & & & & & & & * \\
\hline$\star$ & $\star$ & $\star$ & $\star$ & $\star$ & $\star$ & * & & & & & & & $\star$ & $\frac{1}{0}$ \\
\hline & & & & & & & & & & & & & & $\frac{0}{3}$ \\
\hline$\star$ & $\star$ & $\star$ & $\star$ & * & & & & & & & * & * & $\star$ & $\stackrel{\omega}{2}$ \\
\hline & * & $\star$ & $\star$ & $*$ & & & & & & & $\star$ & & $\star$ & $\frac{\sigma}{0}$ \\
\hline & & & & & & & $\star$ & * & & & & & & ลิ) \\
\hline & & & & & & & & & & & & & & $\lesssim$ \\
\hline & & & & & & & & & $\star$ & $\star$ & & & & $\overline{\mathrm{D}}$ \\
\hline & & & & & & & & & & & & & $\star$ & $\frac{0}{2}$ \\
\hline & & & & & & & & & & & & & & $\frac{\Omega}{D}$ \\
\hline & & & & & & & $\star$ & $\star$ & $\star$ & * & & $\star$ & & $\frac{a}{a}$ \\
\hline$\star$ & $\star$ & $\star$ & $\star$ & $\star$ & & & $\star$ & $\star$ & $\star$ & $\star$ & $\star$ & & $\star$ & $\overrightarrow{0}$ \\
\hline & & & & & & & & & & & & & & $\overrightarrow{0}$ \\
\hline & & & & & & & & & & & & & & $\omega$ \\
\hline & & & & & & & & & $\star$ & $\star$ & & $\star$ & & tk \\
\hline & & & & & & & & & & & & & & 뭉 \\
\hline & & & & & & & $\star$ & $*$ & $\star$ & $\star$ & & & & $\underbrace{0}_{0}$ \\
\hline & & & & * & & & & & & & & $\star$ & $\star$ & एँ \\
\hline & & & & & & & & & & & & $\star$ & $\star$ & $\frac{\infty}{\infty}$ \\
\hline & & & $\star$ & $\star$ & $\star$ & $\star$ & $\star$ & * & $\star$ & $\star$ & * & & & $\frac{7}{4}$ \\
\hline & & $\star$ & $\star$ & & & & & & & & & $\star$ & & $\vec{\infty}$ \\
\hline & & & & & & & & & $*$ & $*$ & $\star$ & & & $\sigma$ \\
\hline
\end{tabular}

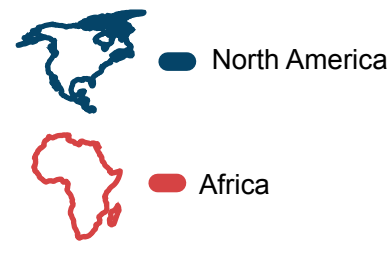

Eurasia

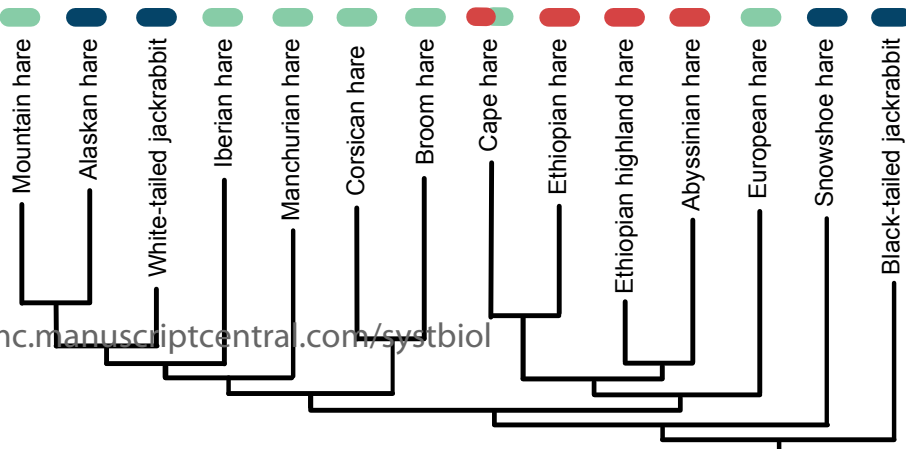




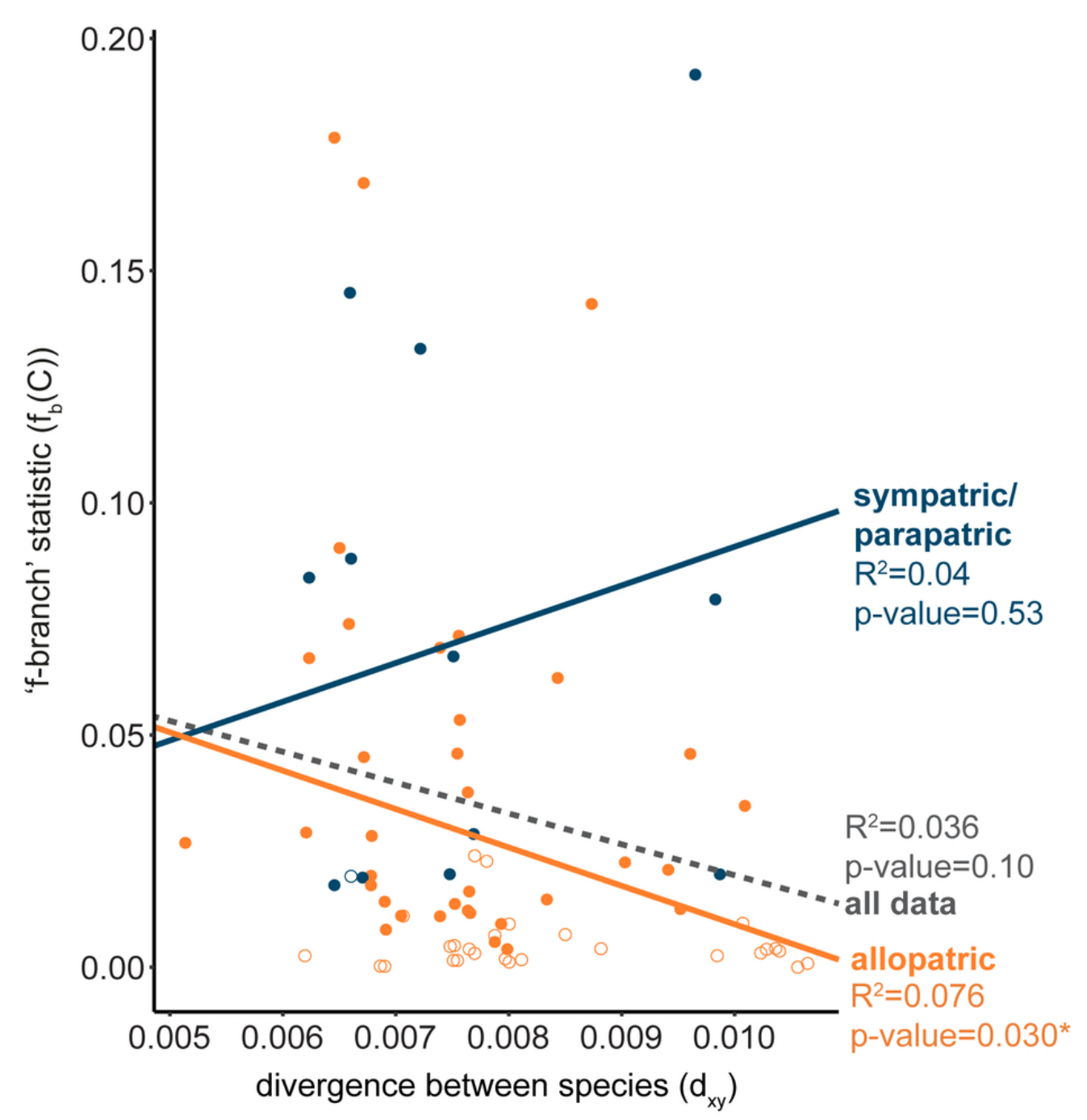

○ not significant • significant • allopatric • sympatric/parapatric

Fig. 4 - Admixture proportions decrease with genetic divergence between allopatric species. We plot the ' $f$ branch' $\left(f_{b}(C)\right)$ values against exome-wide divergence $\left(d_{x y}\right)$ for extant species pairs, differentiating species with overlapping (sympatric/parapatric) or non-overlapping (allopatric) distributions. The tendency line represents a linear regression relating $d_{x y}$ and all (significant and non-significant) $f_{b}(C)$ values calculated with function $\operatorname{Im}()$ in $\mathrm{R}$.

$79 \times 88 \mathrm{~mm}(300 \times 300 \mathrm{DPI})$ 
a)

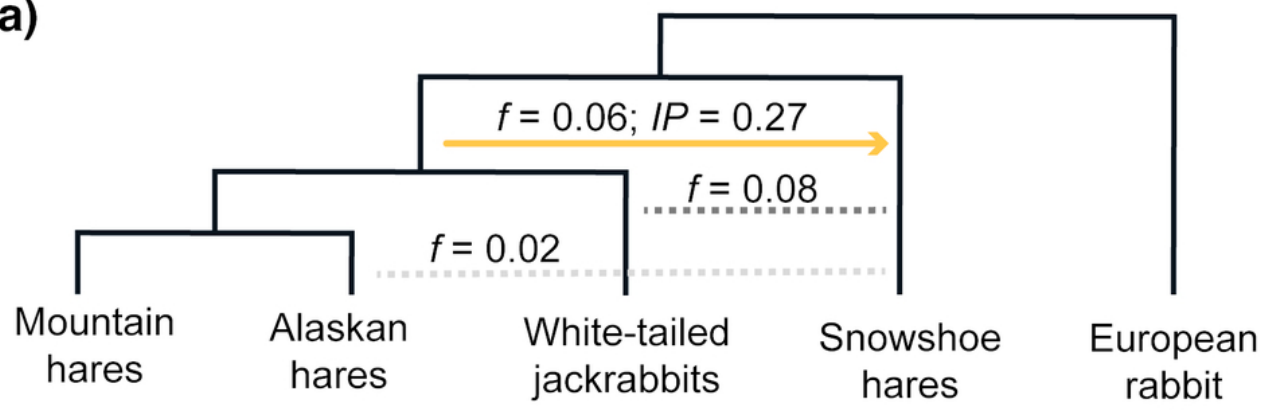

b)
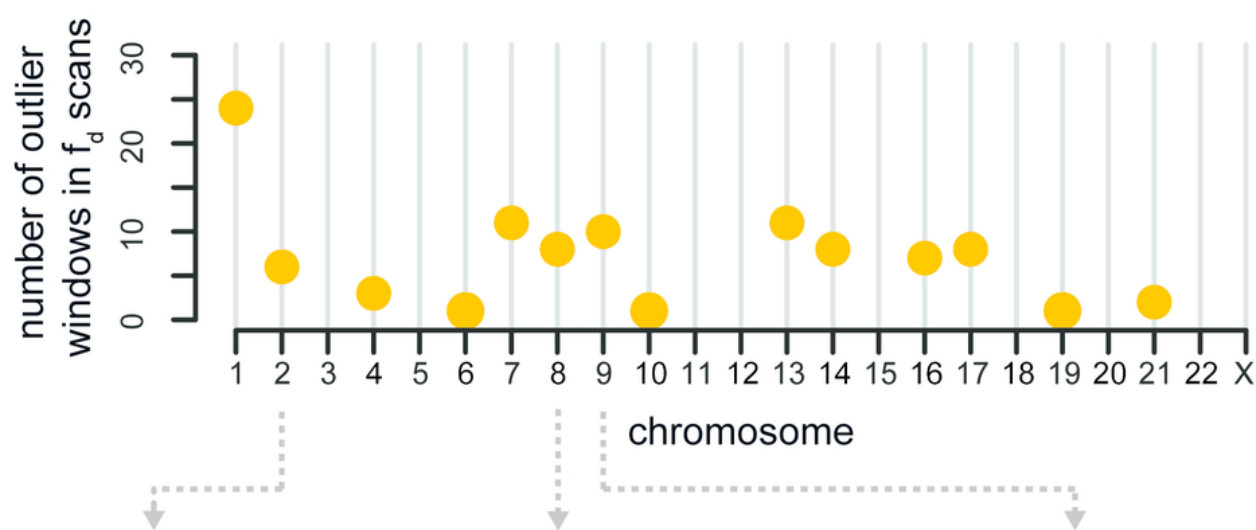

EBF2

(brown fat cell differentiation)

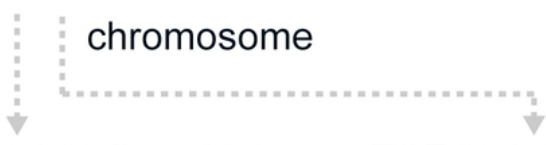

ARNTL2 (circadian clock)

TCF4 (pigmentation) $P D E 6 H$ (visual perception)

Fig. 5 - The impact of ancestral introgression on extant northern latitude species. (a) Events of past and recent admixture inferred in this study involving snowshoe, Alaskan hares, mountain hares and white-tailed jackrabbits. The arrow indicates the direction of ancestral introgression inferred by PhyloNet and 'f-branch' and dashed lines indicate recent introgression inferred with ' $f$-branch'. Values above the lines represent admixture proportion (f) estimated with 'f-branch' or inheritance probability (IP) estimated with PhyloNet; B) Genomic distribution of ancestral blocks of introgression (circles) inferred as shared outlier windows among fraction of admixture $\left(f_{d}\right)$ analysis testing for admixture among snowshoe hares and each one of the three other northern latitude species. Tests were run in $50 \mathrm{~kb}$ genomic sliding windows, and outlier windows are in the top $0.5 \%$ of the $f_{d}$ distribution.

$82 \times 76 \mathrm{~mm}(300 \times 300 \mathrm{DPI})$ 